\title{
Comparison of the third-generation Japanese ocean flux data set J-OFURO3 with numerical simulations of Typhoon Dujuan (2015) traveling south of Okinawa
}

\author{
Akiyoshi Wada $^{1}$ (D) Hiroyuki Tomita ${ }^{2} \cdot$ Shin'ichiro Kako $^{3}$
}

Received: 5 February 2020 / Revised: 13 May 2020 / Accepted: 25 May 2020 / Published online: 12 June 2020

(c) The Author(s) 2020

\begin{abstract}
Insufficient in situ observations in high winds make it difficult to verify climatological data sets and the results of tropical cyclone (TC) simulations. Reliable data sets are necessary for developing numerical models that predict TCs more accurately. This study attempted to compare the third-generation Japanese Ocean Flux Data Sets with Use of Remote-Sensing Observations (J-OFURO3) data, with TC simulations conducted by a $2 \mathrm{~km}$ mesh coupled atmosphere-wave-ocean model. This is a case study of Typhoon Dujuan (2015) and the area of approximately 20N, 130E, south of Okinawa, was selected. The comparison reveals that J-OFURO3 data are reliable for verifying the atmospheric and oceanic components of TC simulations with two different initial sea surface temperature (SST) conditions, although the blank area remains within the inner core area for air temperature, specific humidity, and latent heat flux owing to issues with the construction method. Simulated maximum surface wind speeds (MSWs) are significantly correlated with J-OFURO3 MSWs. The asymmetrical distribution of simulated surface wind speeds within the inner core area can be reproduced well in the J-OFURO3 data set. In terms of the oceanic response to the TC, TC-induced sea surface cooling was reproduced well in the J-OFURO3 data set and is consistent with the simulation results. Unlike simulated SST, simulated surface wind speeds, surface air temperature, and surface specific humidity are still inconsistent with the J-OFURO3 data, even when the J-OFURO3 SST is used as the initial condition. New algorithms, more satellite data used, and model improvement are expected in the future.
\end{abstract}

Keywords J-OFURO3 $\cdot$ Atmosphere-wave-ocean coupled model $\cdot$ Numerical simulation

\section{Introduction}

In the atmosphere and ocean, long-term data sets have been widely used for various purposes such as investigating the mechanisms of coupled atmosphere-ocean variabilities, verifying simulations of numerical models, and developing and understanding the global climate system. As the spatial and temporal resolution of these data sets increases, it is

Akiyoshi Wada

awada@mri-jma.go.jp

1 Meteorological Research Institute, 1-1 Nagamine, Tsukuba, Ibaraki 305-0052, Japan

2 Institute for Space-Earth Environmental Research (ISEE), Nagoya University, F3-1 (200) Furo-cho, Chikusa-ku, Nagoya 464-8601, Japan

3 Graduate School of Science and Engineering, Department of Ocean Civil Engineering, Kagoshima University, 1-21-40 Korimoto, Kagoshima 890-0065, Japan increasingly possible to consider their application for types of research that have not yet been undertaken, such as the ocean response to tropical cyclones (TCs) (e.g., Wada and Usui 2007) and the impact on TC intensity changes (e.g., Wada et al. 2013). Recent satellite remote sensing technologies for earth observations have made it possible to capture a decrease in sea surface temperature (SST) induced by a TC (Lin et al. 2003; Monaldo et al. 1997). However, monitoring the decrease in SST has been undertaken only in the last two decades.

Estimating air-sea surface fluxes such as heat, momentum, and freshwater by using satellite remote sensing techniques is currently achieved in the third generation Japanese Ocean Flux Data Sets with Use of Remote-Sensing Observations (J-OFURO3) (Tomita et al. 2019). Although the spatial resolution of J-OFURO3 is $0.25^{\circ} \times 0.25^{\circ}$ in latitude and longitude is adequate for resolving the inner core of a TC compared with previous similar datasets, there are several challenges associated with estimating changes in 
wind direction around a TC (Tomita et al. 2019). Regarding other atmospheric and oceanic factors, it is not clear which TC characteristics and ocean responses can be analyzed using the daily J-OFURO3 product or to what extent.

The relationship between TCs and SST has long been investigated (Dare and McBride 2011; Evans 1993; Palmén 1948). In the 1990s, monthly mean SST data sets could not express TC-induced sea surface cooling due to coarse temporal and spatial resolutions (Evans 1993). The cooling event has begun to become well known after the 2000s because of the presence of a daily SST data set. This was due to the development of satellite remote sensing technologies for earth observations. The availability of the daily SST data set led to the reconfirmation that SST did vary significantly with depth near the air-sea interface (Kawai and Wada 2007), and air-sea momentum, heat, and freshwater fluxes can affect SST through the advection, mixing, and budget of air-sea net surface flux.

The variation in SST as one of the boundary conditions plays a crucial role in predicting TCs because SST can be an energy source for the evolution of a TC through diabatic heating. This means that accurate air-sea surface fluxes are important for understanding the evolution of a TC and improving TC predictions. It is difficult to verify the airsea surface flux data set around TCs in the J-OFURO3 data set with in situ observations because the opportunity to observe underneath a TC is very rare, with the exception of big observational campaigns such as the Coupled Boundary Layer Air-sea Transfer (CBLAST)-Hurricane program (Chen et al. 2007) and the Impact of Typhoons on the Ocean in the Pacific (ITOP) program (D'Asaro et al. 2011; Pun et al. 2011).

In contrast, numerical simulation studies regarding TCs have increased due to the prevalence of atmosphere-ocean coupled modeling with a horizontal resolution of a few kilometers. Case studies of TCs reveal that numerical simulations have made it possible to calculate TC-induced sea surface cooling to some extent and to improve the prediction of TC intensity more realistically. In addition, various atmospheric and oceanic components can be obtained in a numerical simulation. Although challenging research topics remain with regards to the incompleteness of physical processes, and in the uncertainty of data necessary for solving initial and boundary value problems from external sources, the advantages of numerical simulations are the ability to simulate TC intensification processes and the structural changes in a three-dimensional view.

This study attempts to compare J-OFURO3 data with simulation results conducted by a coupled atmospherewave-ocean model (Wada et al. 2018) in the case of Typhoon Dujuan (2015). The key questions are listed below.
1. To what extent are daily atmospheric and oceanic data such as surface winds, SST, 2 m air-temperature, and $2 \mathrm{~m}$ specific humidity comparable to the simulation results, and is there a significant correlation between J-OFURO3 data and simulation results?

2. Are there any systematic differences between J-OFURO3 data, and simulation results? If the correlation coefficient is low, what is the reason for lowering the value? Do the reasons relate to the spatio-temporal scale of J-OFURO3 data or an algorithm problem in making the datasets?

The study area selected for this analysis is approximately $20^{\circ} \mathrm{N}, 130^{\circ} \mathrm{E}$, south of Okinawa. In the past, the Japan Meteorological Agency was monitoring TCs in this area with a research vessel (Mori et al. 1999; Wada 2005). Some TCs pass over the area and make landfall in Taiwan while others make landfall in Japan; thus, it is important to monitor TCs around the region. In addition, north of $20^{\circ}$ $\mathrm{N}$ in the western North Pacific, warm, and cold eddies frequently originated from baroclinic instability of the weak flow between the westward North Equatorial Current and the eastward Subtropical Countercurrent (Qiu 1999; Lin et al. 2005). A warm upper ocean with a deep mixed layer characterized by warm ocean eddies helps reduce TC-induced sea surface cooling. Such a suppression effect has been reported in the cases of Typhoons Maemi (Lin et al. , 2005; Wu et al. 2007) and Songda (2004; Wada and Usui 2007) in the northwestern Pacific, and it also resulted in an intensification of Atlantic Hurricane Opal (2000) in the Gulf of Mexico (Shay et al. 2000). Analytic errors on the eddies cause TC intensity prediction errors in the framework of the atmosphere-ocean coupled modeling system (Wada 2019). Hence, the accuracy of the initial and boundary conditions necessary for TC predictions are as important as the precision of TC predictions in the current numerical prediction system.

The remainder of this paper is organized into the following sections: Sect. 2 describes the outline of Dujuan. Section 3 explains the data, experimental design, and analysis method used in this study. Section 4 shows the results of the climatological analysis, results of numerical simulations, and comparison of the simulations with J-OFURO3 data. Section 5 discusses model dependency, surface wind speeds, estimates of near-surface temperature, and specific humidity within the inner core of TCs. Concluding remarks are made in Sect. 6.

\section{Typhoon Dujuan (2015)}

Typhoon Dujuan (2015) was upgraded to a tropical cyclone at approximately $16.2^{\circ} \mathrm{N}, 137.5^{\circ} \mathrm{E}$ at $12 \mathrm{UTC}$ on $22 \mathrm{Sep}-$ tember. Dujuan moved west northwestward throughout the 
period from the genesis to landfall in Taiwan. According to the Regional Specialized Meteorological Center (RSMC) Tokyo best track data (https://www.jma.go.jp/jma/jma-eng/ jma-center/rsmc-hp-pub-eg/besttrack.html), the minimum sea-level pressure was $925 \mathrm{hPa}$, with a maximum wind speed of 110 knots (approximately $56 \mathrm{~m} \mathrm{~s}^{-1}$ ) from 00:00 UTC 27 to 06:00 UTC September 28.

Dujuan began to rapidly intensify from 00:00 UTC September 26 at approximately $20^{\circ} \mathrm{N}, 130^{\circ} \mathrm{E}$. In one day, the minimum central pressure decreased by $35 \mathrm{hPa}$, while the maximum wind speed increased by 35 knots. These meet the criteria for rapid intensification according to the Glossary of National Hurricane Center (https://www.nhc.noaa.gov/ aboutgloss.shtml).

\section{Experimental design}

\subsection{Data}

The J-OFURO3 research project provides a data set comprising surface heat, momentum, freshwater fluxes, and related atmospheric and oceanic components over the global oceans (Tomita et al. 2019). The V1.0 data set offers data from 1988 to 2013, with daily temporal resolution and a horizontal resolution of $0.25^{\circ}$. In addition, a preliminary extended data set is available from 2014 to 2017. This study utilized twenty years of J-OFURO3 data spanning 1996-2015. The last year corresponds to the year of Dujuan. Atmospheric and oceanic components archived in the J-OFURO3 data set differ in quality and accuracy due to different construction methods. A brief description of the construction method for the main components is provided below.

SST in the J-OFURO3 data set is an ensemble median obtained from various global SST products listed in Table 3 of Tomita et al. (2019). Most global SST products provided to create the J-OFURO3 data set have already been gridded by combining in situ observations with multi-satellite data. The difference between global SST products depends on the differences in the observation characteristics of each satellite sensor, spatial, and temporal resolution, analysis method, SST representative depth, and other uncertainties. One of the merits of ensemble median SST is to be able to obtain a robust SST without being affected by outliers.

Surface wind speeds are estimated from two types of satellite microwave sensors, which are radiometers and scatterometers. The data obtained from a total of 18 satellite sensors are used to construct the J-OFURO3 surface wind speed data by averaging over a $0.25^{\circ} \times 0.25^{\circ}$ grid space (Tomita et al. 2019). Wind direction is also estimated by an optimal interpolation method because the number of observations with scatterometers is much fewer than that of radiometers even though there are enough observations with WindSat, a satellite-based polarimetric microwave radiometer developed by the Naval Research Laboratory Remote Sensing Division, and the Naval Center for Space Technology for the US.

Near-surface air specific humidity in J-OFURO3 is estimated from multi-channel brightness temperatures measured by multi-satellite microwave radiometers, Special Sensor Microwave Imager (SSMI), Special Sensor Microwave Imager/Sounder (SSMIS), Tropical Rainfall Measurement Mission (TRMM) Microwave Imager (TMI), and Advanced Microwave Scanning Radiometer series (AMSR-E, and AMSR2). The estimation algorithm is based on the relationships between multi-channel brightness temperatures, surface humidity, and the vertical moisture structure (Tomita et al. 2018). The water vapor scale height data were used as an indicator of vertical moisture structure and were obtained from the surface water vapor mixing ratio obtained from the European Centre for Medium-Range Weather Forecasts (ECMWF) reanalysis interim (Dee et al. 2011), and columnar water vapor from multi-satellite microwave radiometers. The daily mean surface air temperature at a height of $2 \mathrm{~m}$ from the surface was obtained from the National Center for Environmental Protection (NCEP)-Department of Energy (DOE) reanalysis 2 (NRA2; Kanamitu et al. 2012) atmospheric reanalysis data.

The daily mean latent heat flux is calculated by using a bulk method, COARE3.0 that was proposed by Fairall et al. (2003). Detailed configuration of the COARE3.0 model in the J-OFURO3 data set was introduced in Tomita et al. (2019).

The RSMC Tokyo best track data set was used to verify the location and intensity of a simulated TC. The Japanese 55-year Reanalysis (JRA-55) 6-h product with the horizontal resolution of $1.25^{\circ} \times 1.25^{\circ}$ (Kobayashi et al. 2015) was used for comparison with the J-OFURO3 data and simulation results.

We used the Four-dimensional variational Ocean ReAnalysis data set for the Western North Pacific (FORA) spanning 1996-2015 (FORA-WNP30; https://synthesis. jamstec.go.jp/FORA/e/index.html; Usui et al. 2017). The horizontal resolution of the North Pacific version of the data set was $0.5^{\circ}$ in the longitude-latitude coordinate system. We also used the Microwave Optimally Interpolated SST (MW OISST, hereinafter OISST) daily product obtained from the Remote Sensing Systems site (https:// www.remss.com/). OISST is the daily merged satellite data set that includes two satellite SST data sets measured by TRMM/TMI and AMSR-E satellite radiometers. OISST covers the global ocean with a $0.25^{\circ}$ horizontal spacing at a depth of approximately $1 \mathrm{~m}$. The value of OISST was corrected using a diurnal model, which represents the daytime temperature at 12 o'clock. 


\subsection{Model.}

The atmosphere-wave-ocean coupled model used in this study has been used in many TC studies to understand the role of the ocean on TC predictions (e.g. Wada et al. 2018; Wada and Oyama 2018; Oyama and Wada 2019). The coupled model is constructed based on a nonhydrostatic atmospheric model (NHM; Saito 2012), a Meteorological Research Institute (MRI) third-generation ocean surfacewave model (MRI-III, Japan Meteorological Agency 2013), and an MRI multilayer ocean model developed based on Bender et al. (1993).

The NHM includes microphysics expressed in an explicit three-ice bulk microphysics scheme (Ikawa and Saito 1991; Lin et al. 1983), air-sea momentum, sensible, and latent heat fluxes with exchange coefficients for air-sea momentum and enthalpy transfers over the sea-based on bulk formulae (Kondo 1975) or, when the ocean-wave model is coupled (Wada et al. 2010) based on the roughness lengths proposed by Taylor and Yelland (2001), a sea spray formulation with whitecap coverage of only approximately $4 \%$ under TC conditions (Wada et al. 2018), a turbulent closure model (Klemp and Wilhelmson 1978; Deardorff 1980), and a radiation scheme (Sugi et al. 1990).

The MRI-III predicts wave spectra as a function of space and time from an energy balance equation composed of the spectral energy input by the wind, the nonlinear transfer of spectral energy due to wave-wave interactions and the dissipation of energy due to breaking surface waves and whitecap formation. The wave spectrum had 900 components, each associated with one of 25 frequencies and one of 36 directions. The frequency of the wave spectrum was divided logarithmically from 0.0375 to $0.3000 \mathrm{~Hz}$.

The MRI multilayer ocean model employs a reduced gravity approximation and a hydrostatic approximation, and it is assumed that the water is a Boussinesq fluid. The model has three layers and four interfaces at maximum. The uppermost layer is the mixed layer at which the density is vertically uniform. The middle layer is the seasonal thermocline, where the vertical temperature gradient is greatest. The bottom layer is assumed to be undisturbed by entrainment. The four levels are the sea surface, the base of the mixed layer, the base of the thermocline, and the sea bottom. The model calculates the water temperature and salinity at the surface and at the base of the mixed layer, the thickness of each layer, and horizontal flows between layers. The entrainment rate is calculated only at the base of the mixed layer (Deardorff 1983).

The following procedures are exchange processes between the NHM, MRI-III, and MRI multilayer ocean models, which are not modified from Wada et al. (2018). Each time step of the NHM, MRI-III, and MRI multilayer ocean model is explained in Sect. 3.3. Shortwave and longwave radiation, air-sea sensible, latent heat fluxes, wind stresses, cloud cover, and precipitation were calculated by the NHM and used in the MRI multilayer ocean model at every time step in the MRI multilayer ocean model. SST calculated by the MRI multilayer ocean model was instead used in the atmospheric model at every time step in the MRI multilayer ocean model. Wind speeds calculated by the NHM were provided to the MRI-III at every time step of the MRI-III. Wave heights calculated by the MRI-III were provided to the NHM to calculate the steepness of the ocean wave for estimating surface roughness lengths. The ocean currents at the uppermost layer calculated in the MRI multilayer ocean model were provided to the MRI-III at every time step of the MRI-III. The group velocity of ocean waves calculated by the MRI multilayer ocean model was modified by the ocean currents in the uppermost layer. Wave-induced stresses calculated by the MRI-III were provided to the MRI multilayer ocean model to modify the surface wind stress. The waveinduced stress was also used for estimating the entrainment rate of breaking surface waves.

\subsection{Experimental design}

In this study, the initial time and integration period for the numerical simulation of Dujuan were 00:00 UTC on September 23,2015 , and $120 \mathrm{~h}$ with a time interval of $3 \mathrm{~s}$ for the NHM, $18 \mathrm{~s}$ for the multilayer ocean model, and 6 min for the MRI-III. The computational domain was approximately $2360 \mathrm{~km} \times 2160 \mathrm{~km}$ for the $2 \mathrm{~km}$-mesh NHM and the coupled model. There were 55 levels in vertical coordinates, with the intervals ranging from $40 \mathrm{~m}$ for the near-surface layer to $1180 \mathrm{~m}$ for the uppermost layer in all experiments. The top height was approximately $27 \mathrm{~km}$.

The Japan Meteorological Agency (JMA) global objective analysis with a horizontal resolution of $20 \mathrm{~km}$ and the FORA North Pacific Ocean analysis with a horizontal resolution of $0.5^{\circ}$ were used for creating initial atmospheric and oceanic conditions as well as atmospheric lateral boundary conditions. For comparison, a numerical simulation was performed by the uncoupled NHM with the same initial and boundary conditions.

This study conducted two numerical simulations that differed in the initial condition of sea surface temperature. One used OISST, and the other used SST in the J-OFURO3 data set. The list of numerical simulations is shown in Table 1.

\subsection{Analysis method}

The target location is $20^{\circ} \mathrm{N}, 130^{\circ} \mathrm{E}$; therefore, the analysis area was set to cover the area at $18-24^{\circ} \mathrm{N}$ and $127-133^{\circ}$ E. Before observing the results of the comparison between the J-OFURO3 data and simulation results, we preliminarily investigated the climatological characteristics (maximum 
Table 1 The list of numerical simulations

\begin{tabular}{lll}
\hline Experiment name & Model & Ocean data at the initial time \\
\hline NHMOI & NHM & OISST \\
CPLOI & $\begin{array}{l}\text { Atmosphere- } \\
\text { wave-ocean } \\
\text { coupled model }\end{array}$ & OISST + FORA \\
& NHM & J-OFURO3 \\
NHMJF & $\begin{array}{l}\text { Atmosphere- } \\
\text { wave-ocean } \\
\text { CPLJF }\end{array}$ & J-OFURO3 + FORA \\
& coupled model & \\
& & \\
\hline
\end{tabular}

surface wind speed, central pressure, SST, and TC-induced sea surface cooling) of TCs passing over the analysis area from September to November.

In this study, atmospheric and oceanic components such as SST $\left({ }^{\circ} \mathrm{C}\right)$, surface wind speed $\left(\mathrm{m} \mathrm{s}^{-1}\right), 2 \mathrm{~m}$ air temperature $\left({ }^{\circ} \mathrm{C}\right), 2 \mathrm{~m}$ specific humidity $\left(\mathrm{g} \mathrm{kg}^{-1}\right)$, and air-sea latent heat flux $\left(\mathrm{W} \mathrm{m}^{-2}\right)$ in the J-OFURO3 data set were compared with the results of numerical simulations. The domain for the comparison covers the area from $16^{\circ} \mathrm{N}$ to $32^{\circ} \mathrm{N}$ and $122^{\circ} \mathrm{E}$ to $138^{\circ} \mathrm{E}$, which is wider than the analysis area because the moving speed was relatively rapid when the TC passed the analysis area. At approximately $20^{\circ} \mathrm{N}$ and $130^{\circ} \mathrm{E}$, the location of the simulated storm was close to that of the best track, although the northward bias was found west of $130^{\circ}$ E. The comparison was made between September 24 and 25, in 2015 at approximately $20^{\circ} \mathrm{N}$ and $130^{\circ} \mathrm{E}$.

The atmospheric and oceanic components such as 6-hourly SST, surface wind speed, $2 \mathrm{~m}$ air temperature, $2 \mathrm{~m}$ specific humidity, and air-sea latent heat flux simulated by the $2 \mathrm{~km}$-mesh coupled model were averaged over a $0.25^{\circ}$ $\mathrm{x} 0.25^{\circ}$ grid, corresponding to the horizontal resolution of the J-OFURO3 data set. Correlations between the simulation results and J-OFURO3 data were then investigated for each atmospheric and oceanic component, from 12:00 UTC September 24 to 06:00 UTC September 25, after correcting the difference of the location of the TC between the simulation and the best-track analysis. The range of the difference was within three grids (less than $1^{\circ}$ ).

It should be noted that the TC position for the best track and simulation results were determined based on the location of the lowest sea-level pressure. Conversely, there are no data on sea-level pressure in the J-OFURO3 data set. The distribution of surface winds in the J-OFURO-3 dataset was determined by optimally interpolating the incoming satellite data, and the time at the TC position depended on the time of the incoming data. Therefore, although the difference in positions caused by the TC movement within one day affected the verification results to some extent, this study assumed the center position of Dujuan in the J-OFURO3 data set as the average of the 6-hourly best track center positions during the analysis period (1 day).

\section{Results}

\subsection{Climatology}

The scale of a TC varies from a few $100-1000 \mathrm{~km}$ in size when it measured by a domain surrounded with an isobar of $1000 \mathrm{hPa}$. The environmental vertical shear is defined as the difference in wind speeds between 200 and $850 \mathrm{hPa}$ levels and is often determined within a radius of $500-800 \mathrm{~km}$ from the TC center. Therefore, this study defined a TC scale within a domain from $6^{\circ} \times 6^{\circ}$ in a latitude-longitude coordinate system. This scale corresponds to the size of the analysis domain in Sect. 3.4.

The number of TCs that passed over the square domain of $18-24^{\circ} \mathrm{N}$ and $127-133^{\circ} \mathrm{E}$ from September to November was 50 during 1996-2015 (Fig. 1). This corresponded to approximately $26.2 \%$ of the total number of $191 \mathrm{TCs}$ in the western North Pacific. Six TCs were relatively weak and corresponded to the genesis phase when they passed over the target domain. The TC with the longest duration (7.5 days) over the domain was Typhoon Prapiroon (2012), followed by Typhoons Kirogi (2005, 4.5 days), Nabi (2005, 3.25 days), and Dujuan (2015, 3.25 days).

Figure 2a shows the maximum surface winds (MSWs) relationship between the RSMC Tokyo best track data set, and the J-OFURO3 data set. Maximum surface winds in the

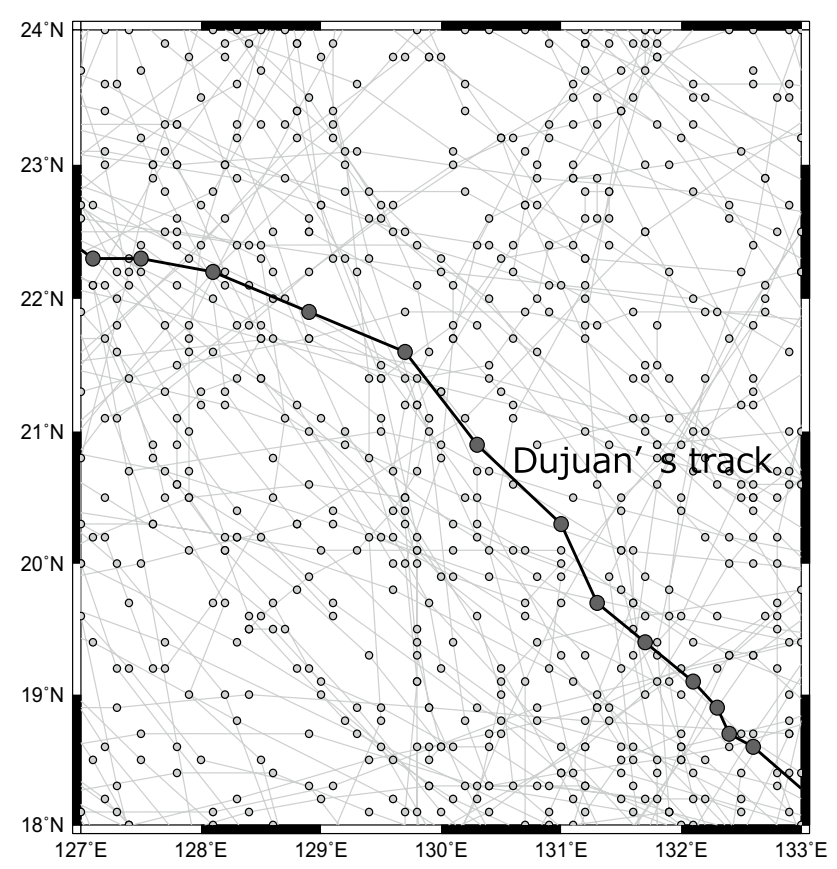

Fig. 1 Track of Typhoon Dujuan (2015) and locations of TCs from September to November from 1996 to 2015. Circles with solid lines indicate the track of Dujuan. Small circles with gray lines indicate the location and track of TCs every $6 \mathrm{~h}$ in the RSMC best track data 
(a)

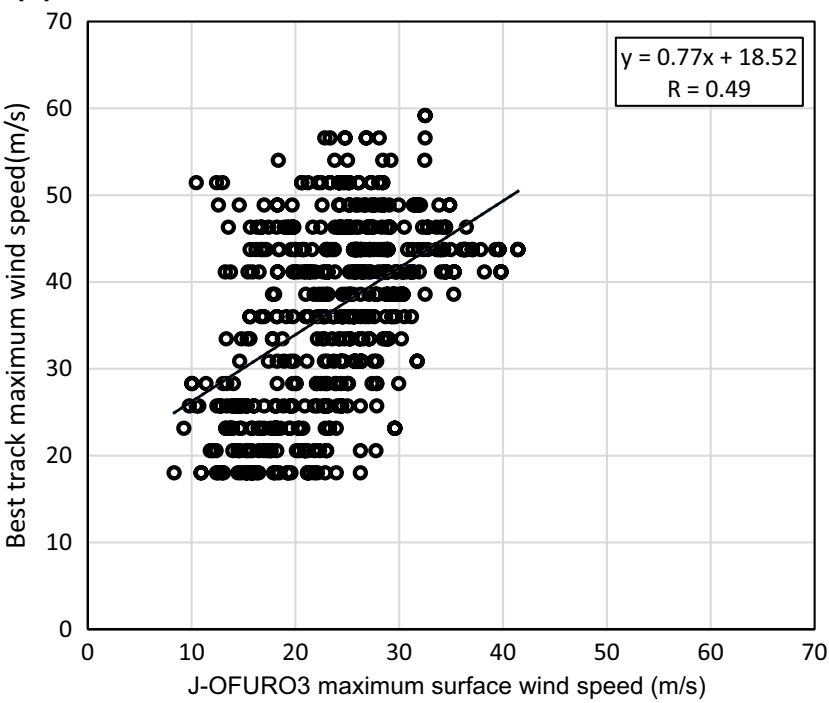

Fig. 2 Scatter diagram on the relation of maximum surface wind speeds a between the RSMC best track data and J-OFURO3 data and b between the RSMC best track data and JRA-55 data. The dashed

$\mathrm{J}$-OFURO3 data set were estimated within a $2.75^{\circ} \times 2.75^{\circ}$ box, centered at the best track TC position every $6 \mathrm{~h}$. For comparison, the relationship between the RSMC Tokyo best track data set and the JRA-55 data set was also investigated (Fig. 2b). It should be noted that unlike the JRA-55 data set, the finest temporal resolution of the J-OFURO3 data set is daily, and therefore, the J-OFURO3 data set cannot capture rapid changes in MSWs that occurred within a day. Nevertheless, the relationship between the RSMC Tokyo best track data and the J-OFURO3 data was significantly correlated. The correlation was also significant between

(a)

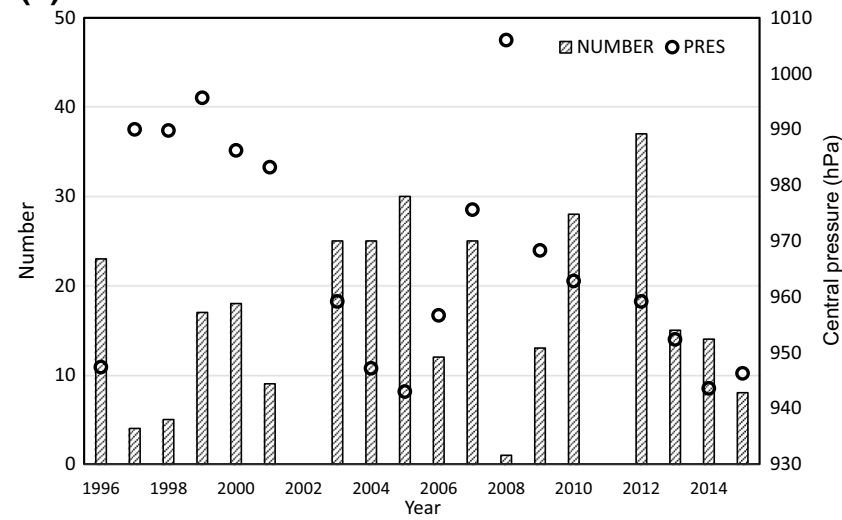

Fig. 3 Time series of the number of samples with the average of best track central pressure over the area of $18-24^{\circ} \mathrm{N}$ and $127-133^{\circ} \mathrm{E}$ from September to November during 1996-2015 a in the RSMC best track data set and $\mathbf{b}$ in the JRA-55 data set. The difference of the number (b)

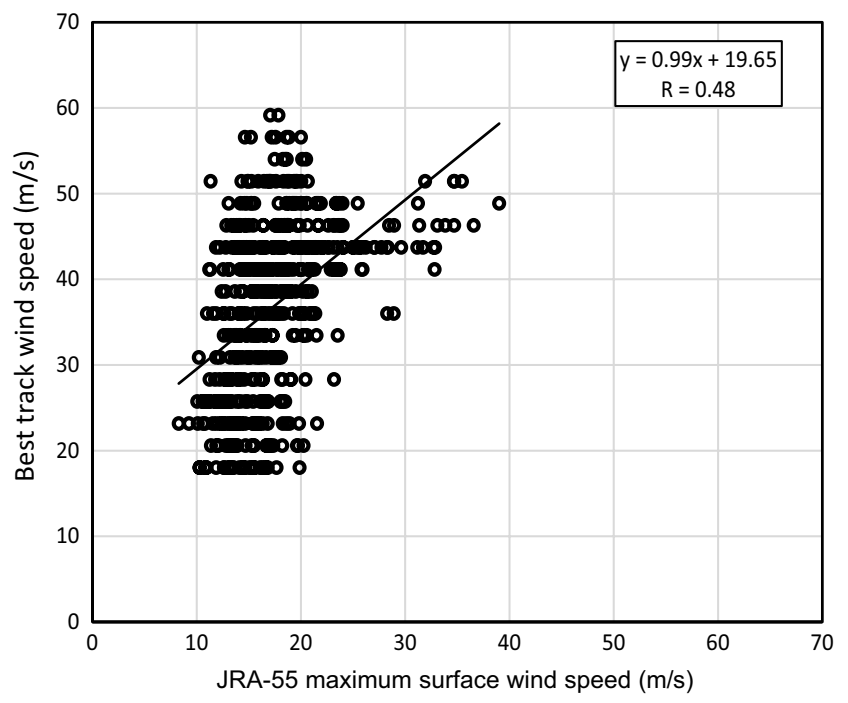

line indicates the linear correlation with the formula and correlation coefficient, respectively

the RSMC Tokyo best track data set and the JRA-55 data, but both MSWs in the J-OFURO data set and the JRA-55 data set have a negative bias for MSWs in the RSMC best track data set. This suggests that high MSW analyzed in the RSMC best track data set cannot be reproduced in both the J-OFURO3 and JRA-55 data sets.

Figure 3 shows the time series of the cumulative number of TCs passing over the analysis area and the mean central pressure each year, averaged over twenty years, from 1996 to 2015. The number of TCs varied depending on the year. The number of TCs in 2012 was the highest, while the mean

(b)

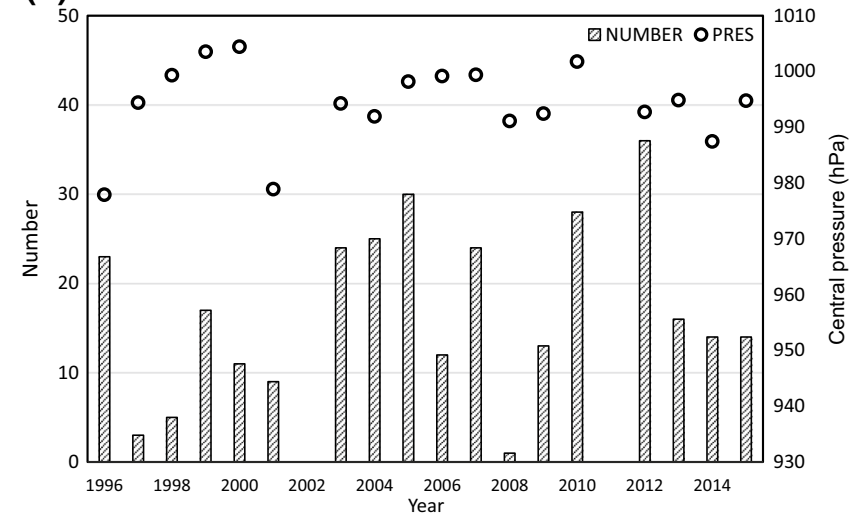

in each year is caused by the difference of the time interval of two datasets: The RSMC best track data set includes 3-h data, while the JRA-55 data set only includes 6-h data 
central pressure in 2005 and 2014 was the lowest. The intensity of TCs passing over the analysis area tended to increase significantly during 1996-2015, with a $t$ value of 1.85 , corresponding to the $t$ test $99 \%$ significant level.

Figure 4a shows the time series of mean SST in each year in the J-OFURO3 data set from 1996 to 2015. There is no correlation between mean SST and mean central pressure on TCs passing over the analysis area (not shown). This study defines sea surface cooling as the difference in daily SST in each grid between pre-three days and post-three days when a TC exists in the analysis area. Figure $4 \mathrm{~b}$ shows the time series of sea surface cooling in the J-OFURO3 data set. The number of TCs in 2012 is the highest, while daily mean SST is relatively low (Fig. 4a). Differing from the time series of mean SST, the amplitude of mean sea surface cooling tends to linearly increase significantly during 1996-2015 with the $t$ value of 3.38, corresponding to the $t$ test $99 \%$ significant level. Therefore, as TC intensity increased from September to November from 1996 to 2015, the SST became increasingly lower underneath a TC.

It should be noted that the impact of the mixture of bulk and skin temperature on the time series of SST was small. This is because there was no trend of SST in the J-OFURO3 data set during 1996-2015, despite an increase in the number of satellite observations, while in situ observations near the sea surface decreased. The number of satellite microwave radiometers and scatterometers available to construct the J-OFURO3 data set was 3 and 2, respectively, in 1996 but increased to 5 and 3, respectively, in 2013 (see Fig. 1 in Tomita et al. 2019). Relatively strong winds stir the upper ocean deeply and the layer of skin temperature is destroyed during the passage of a TC. In addition, MSWs in the RSMC Tokyo best track data are

(a)

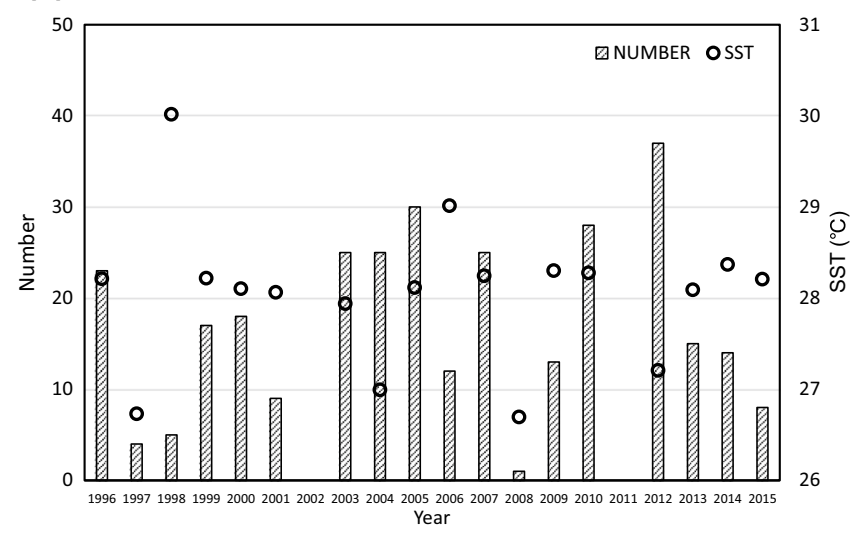

Fig. 4 Time series of the number of samples with the averages of a SST in the J-OFURO3 dataset and $\mathbf{b}$ decreases in SST during the period from the pre- 3 days to the post- 3 days with the standard devia- closely related to central pressures based on Koba's relationship (Koba et al. 1990). Based on these prerequisitesand from a climatological viewpoint-the J-OFURO3 data set showed that increases in TC intensity resulted in decreasing SST underneath a TC by the passage of a TC over the analysis area. The increasing trend of TC intensity cannot be captured in the JRA-55 data set (Fig. 3b), and in that sense, the characteristics of the J-OFURO3 data set differ from those of the JRA55 data set. The question remained of which dataset was more realistic for studying TCs on a weather forecasting time scale.

\subsection{Simulation results}

It is very rare to directly observe the central pressure of a TC and the horizontal distribution of surface wind speed, particularly in the western North Pacific. The opportunity for aircraft observations within the inner core of a TC is so rare that it is difficult to obtain the entire TC wind distribution every $6 \mathrm{~h}$, which is the time interval of the RSMC best track data and the JRA55 data set. To determine the TC wind distribution at shorter intervals, a model-based numerical simulation is effective, but there is an acknowledged problem that TC wind distribution differs depending on the numerical model used (Kanada et al. 2017). In this study, numerical simulations of Dujuan were conducted by using numerical models (see Sect. 3.2) that have been frequently used in TC case studies. The simulation results were then compared with the J-OFURO3 data for all atmospheric and oceanic components.

Figure 5a, b show the RSMC best track and two simulated tracks of Dujuan. These simulation tracks were obtained from two simulation results by the NHM and the coupled model (hereafter, CPM), respectively. The difference between simulations illustrated in Fig. 5a, b is SST at (b)

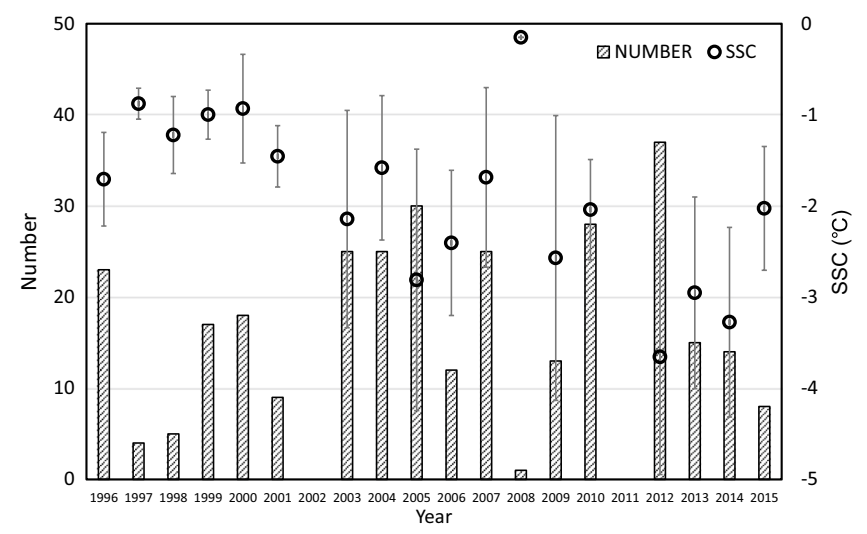

tion over the area of $18-24^{\circ} \mathrm{N}$ and $127-133^{\circ} \mathrm{E}$ from September to November during 1996-2016 
(a)

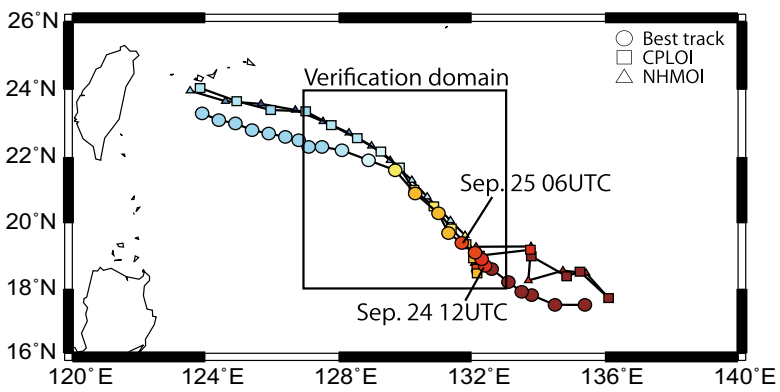

(b)

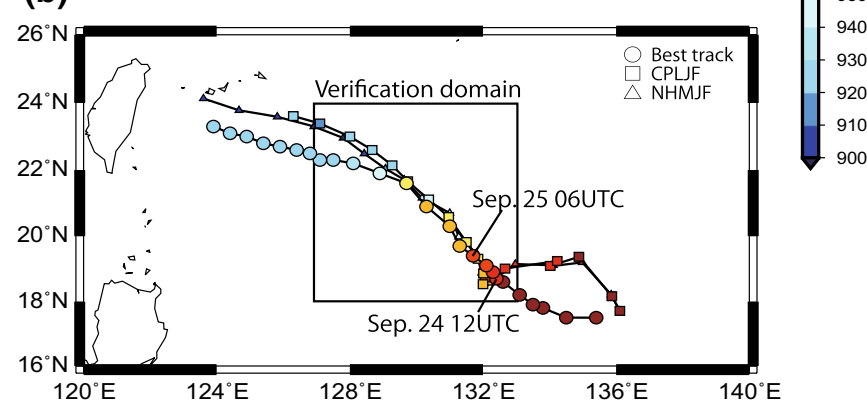

Fig. 5 Tracks of Typhoon Dujuan and difference in SST between OISST and J-OFURO3 on September 23 in 2015. (Left panels) Circles with the solid lines indicate the best track of Dujuan. Squares with the solid lines indicate the simulation results in the a CPLOI and b CPLJF experiments. Triangles with the solid lines indicate the sim-

the initial time: one used the OISST data set while the other used the J-OFURO3 data set. Figure $5 \mathrm{c}$ shows the horizontal distribution of the difference in SST between the two data sets. In the verification domain, the SST in the OISST data set, particularly east of $130^{\circ} \mathrm{E}$ is higher than that in the J-OFURO3 data set.

The central position of simulated TCs was determined by first determining the location of minimum central pressure and then by determining the location of the lowest wind speed within a domain where the simulated central pressure was within $+4 \mathrm{hPa}$ from the lowest central pressure. The location was finally determined as the central position of the simulated TC. This procedure helped to ensure that the location of the mesovortex generated near the TC center, and within the radius of MWS, was not mistaken for the central position of the simulated TC.

The simulated track was similar to the RSMC best track from 12:00 UTC on September 24 to 06:00 UTC on September 25 (Fig. 5). Compared with the RSMC best track, the simulated TC thereafter tended to move northward. The analysis period for comparison was from 12:00 UTC on September 14 to 06:00 UTC on September 25.

Figure 6 shows the time series of the RSMC best track central pressure, and two simulated central pressures. In Fig. 6, the period from 12:00 UTC on September 24 to 06:00

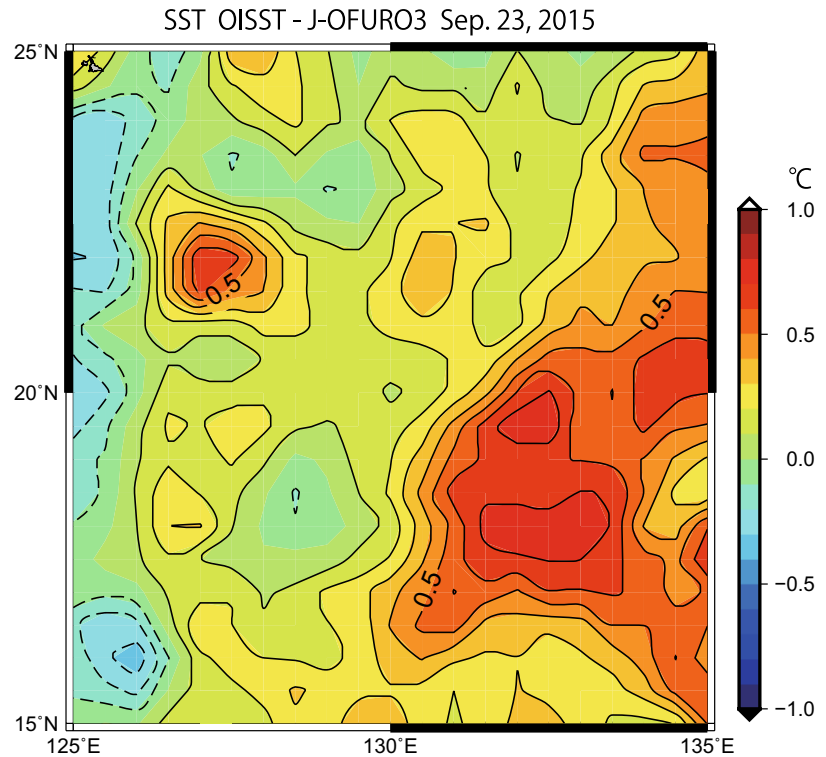

ulation results in the a NHMOI and b NHMJF experiments. Verification domain is shown as a big square. Colors in each circle indicate the value of central pressure. (Right panel) $\mathbf{c}$ Colors indicate the difference in SST between OISST and J-OFURO3 on September 23 in 2015 (OISST-J-OFURO3) (color figure online)

UTC on September 25 corresponds to the intensification phase; therefore, this study only demonstrates the availability of J-OFURO3 on TC studies in the intensification phase. Most of the simulated TC intensity shows overdevelopment, compared with the RSME best track TC intensity. After 12:00 UTC on September 25, central pressures simulated by the CPM increased due to TC-induced sea surface cooling. Although the simulated track shifted northward during the period, the variation in central pressures simulated by the CPM was more consistent with the RSMC best track central pressures than that simulated by the NHM. The difference in SST at the initial time between the OISST data set and the J-OFURO3 data set (Fig. 5c) resulted in a difference in simulated central pressures (Fig. 6). In addition, the difference in intensity changes differed between simulation results by the NHM, and the CPM. Understanding the differences in TC intensity simulations caused by the SST at the initial time will contribute to improving the TC intensity prediction by developing the numerical model.

\subsection{Comparison}

The advantage of the J-OFURO3 data set is that it includes historical surface flux data such as daily-mean wind stresses, sensible, and latent heat fluxes with a horizontal resolution 
(a)

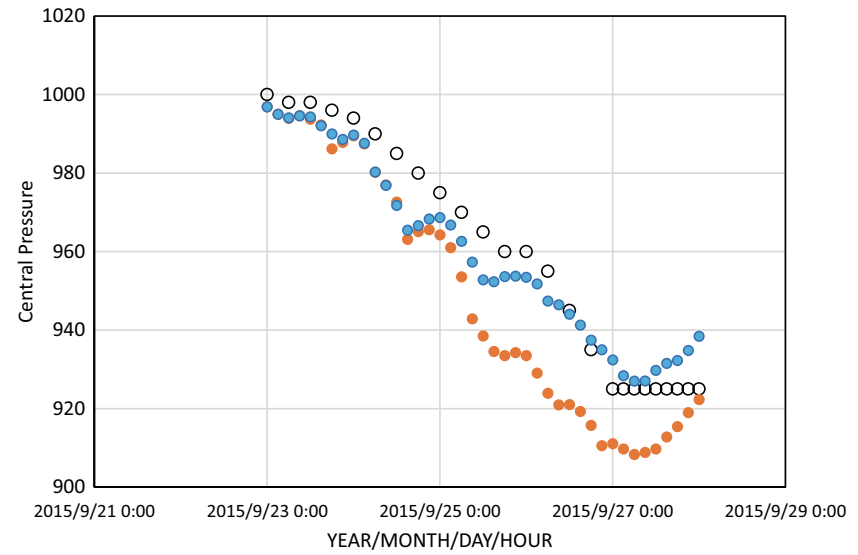

Fig. 6 Time series of central pressures. Open circles indicate the best track central pressure of Typhoon Dujuan. Orange circles indicate the simulation results in the a NHMOI and b NHMJF experiments.

of $0.25^{\circ}$, which is higher than that of JRA-55 and other atmospheric data sets for climatological use. These values are calculated based on atmospheric, and oceanic components such as surface wind speeds, SST, $2 \mathrm{~m}$ air temperature, and $2 \mathrm{~m}$ specific humidity. Therefore, the components and air-sea latent heat flux in the J-OFURO3 data set were compared with the simulation results. For surface wind speeds, JRA55 was also considered in the comparison. Air-sea latent heat flux was selected because the main energy source for TC intensification is latent heat flux (Emanuel 1986, 1995). This is the reason that wind stresses and sensible heat fluxes were not compared. For estimating wind stresses, in addition to errors in surface wind speeds, the difference in drag coefficients between the data set and simulation results makes it unsuitable for comparison. The drag coefficient in the CPM is calculated based on wave heights, and roughness length (b)

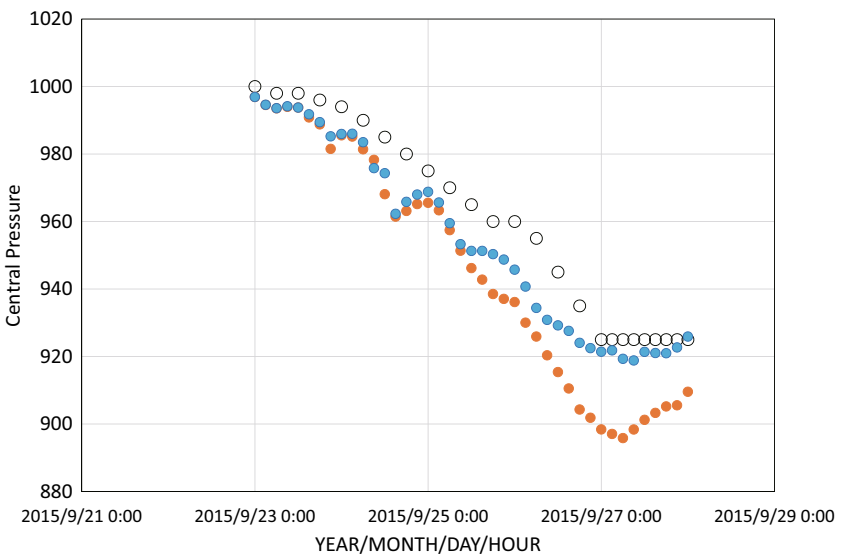

Light blue circles indicate the simulation results in the a CPLOI and b CPLJF experiments (color figure online)

so that the CPM can simulate the level-off of drag coefficient under high winds within the inner core of a TC (Wada et al. 2013). The drag coefficient in the NHM, however, strongly depends on surface wind speeds. The drag coefficient in the J-OFURO3 is based on Fairall et al. (2003), which differs from the two coefficients mentioned above.

\subsubsection{Surface wind speeds}

The scatter diagrams in Fig. 7 indicate the significance of linear correlation in surface wind speeds between J-OFURO3 data and simulation results, with $t$ values of 31.7 (CPLOI), and 27.4 (CPLJF), which corresponds to the $t$ test 99\% significant level. The correlation in the OISST experiment is relatively high compared with that in the J-OFURO3 experiment. The plots are separated into two branches when either (a)

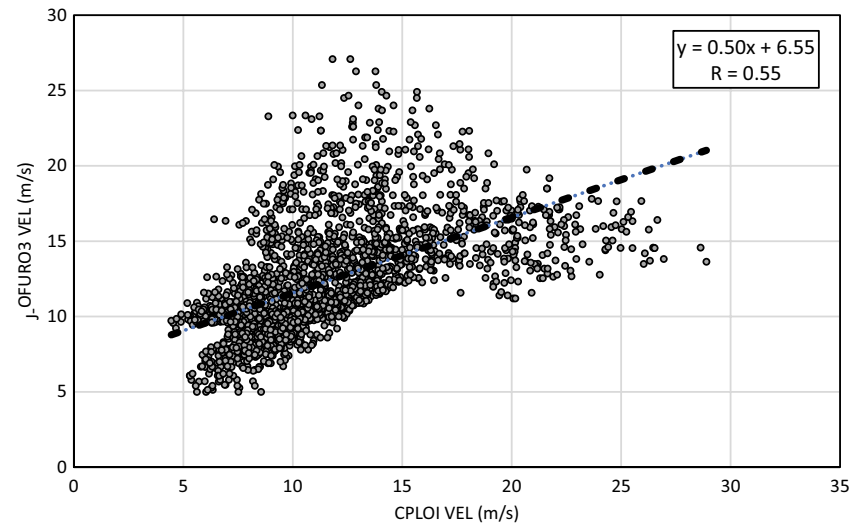

(b)

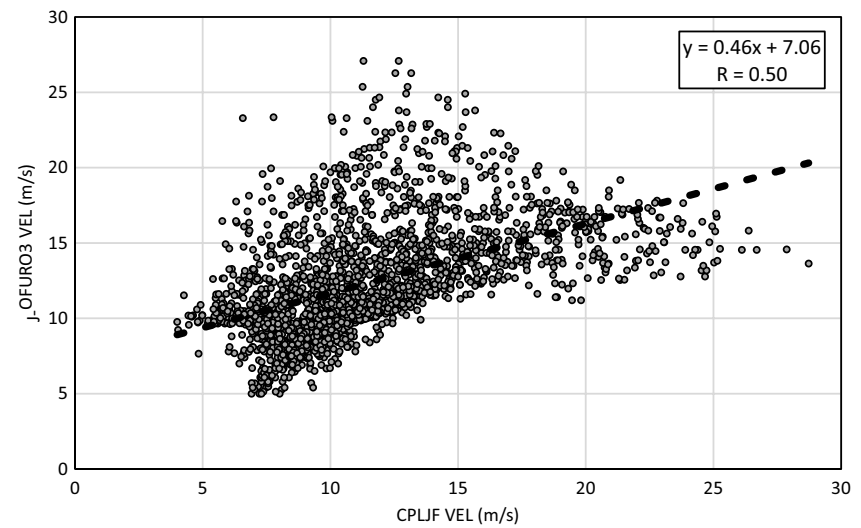

Fig. 7 The relationship of wind speeds between J-OFURO3 data and simulation results. Scatter diagrams indicate the relationship. The dashed line in each panel indicates the linear correlation with the formula and correlation coefficient in the a CPLOI and b CPLJF experiments 
surface wind speed is high. This is probably related to the difference in the TC center position between the simulation result, and the J-OFURO3 data set, and the difference in the horizontal resolution between them $(0.25$ in the J-OFURO 3 data set, and $2 \mathrm{~km}$ in the simulation results). The impact of the difference of horizontal resolution on the spread of simulated surface wind speeds in a grid of J-OFURO3 is discussed in Sect. 5.

The horizontal distribution of surface wind speeds in the J-OFURO3 data set shows a wave- 1 asymmetric pattern (Fig. 8a), which is consistent with the two simulation results (Fig. 8b, c). The radius of simulated MSW is approximately $30 \mathrm{~km}$, and therefore, the J-OFURO3 data set barely captures the radius. In contrast, the JRA-55 data set could not reproduce the radius of MSW (Fig. 8d). This indicates that surface wind speed data in the J-OFURO3 data set has an advantage in the sense that it can reasonably express the inner-core asymmetry of a TC.

\subsubsection{Sea surface temperature}

Unlike the results of surface wind speeds, the correlation coefficient of SST in the J-OFURO3 experiment is higher than that of the OISST experiment, although the linear correlation between best track data and simulation results is significant with the $t$-values of 21.7 (CPLOI) and 39.7 (CPLJF), corresponding to the $t$ test 99\% significant level (Fig. 9). The difference in the correlations is due to errors attributable to the SST at the initial time. The horizontal distribution of SST in the J-OFURO3 data set clearly shows sea surface cooling after the passage of Dujuan (Fig. 10a). The simulation results regarding TC-induced sea surface cooling (Fig. 10b, c) are consistent with the sea surface cooling analyzed in the J-OFURO3 data set. Furthermore, sea surface cooling in the CPLOI, and CPLJF experiments is slightly smaller than in the J-OFURO3 data set except for at approximately $18^{\circ} \mathrm{N}, 133^{\circ}$ $\mathrm{E}$ in the CPLJF experiment (Fig. 10c), when the central TC position differs between the J-OFURO3 data and simulation results during the early intensification phase (Fig. 5).

The correlation coefficient of SST is higher in the CPLJF experiment than in the CPLOI experiment (Fig. 9). This indicates that the accuracy of the SST at the initial time is reflected in the following simulation results. For the central pressure during the mature phase, a simulated central pressure in the CPLJF experiment is closer to the best track central pressure than that in the CPLOI experiment (Fig. 6).
Fig. 8 Horizontal distribution of wind speeds a in the J-OFURO3 data set, $\mathbf{b}$ in the CPLOI experiment, $\mathbf{c}$ in the CPLJF experiment, and $\mathbf{d}$ in the JRA-55 dataset. The J-OFURO3 data set is a daily product, while the simulation results and JRA55 data are the average from 12:00 UTC September 24 to $06: 00$ UTC September 25. The contour interval is $2.5 \mathrm{~m} \mathrm{~s}^{-1}$ (a)

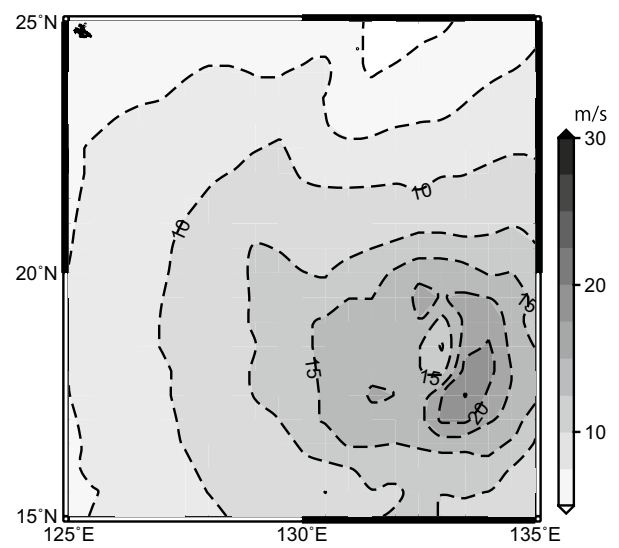

(C)

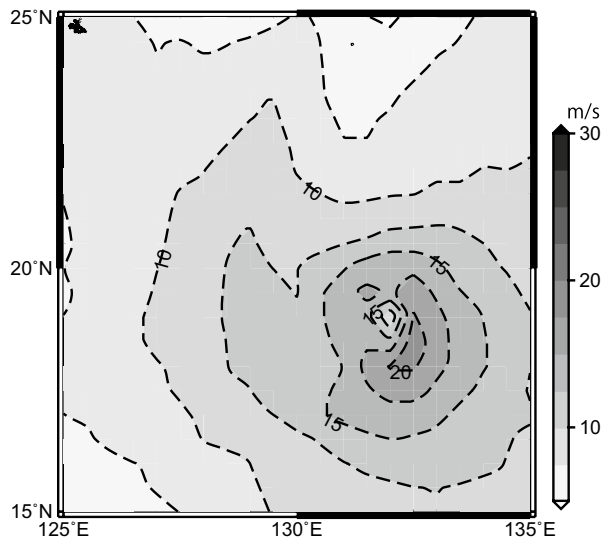

(b)

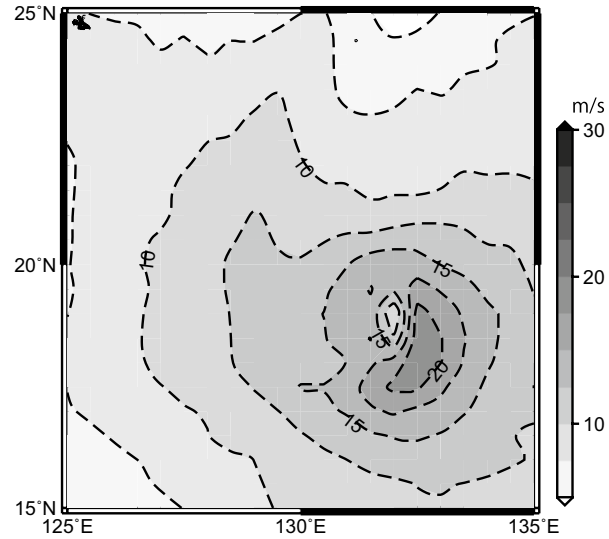

(d)

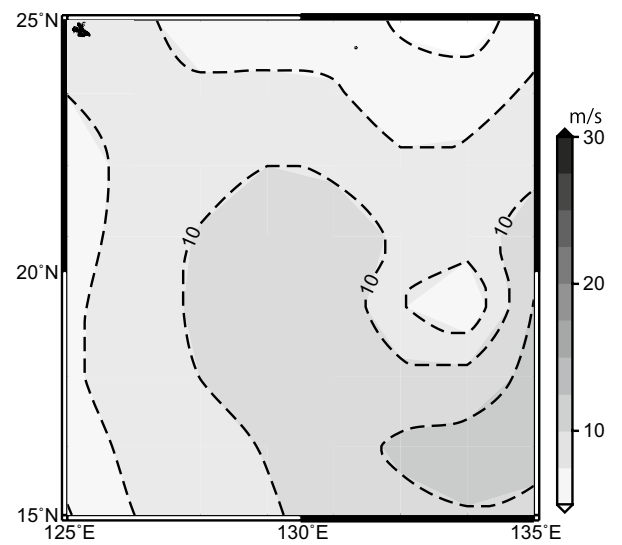


(a)

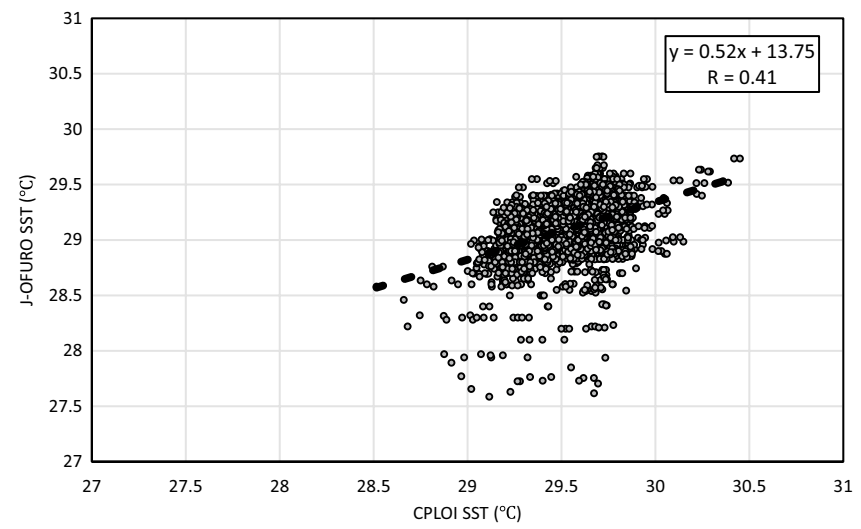

(b)

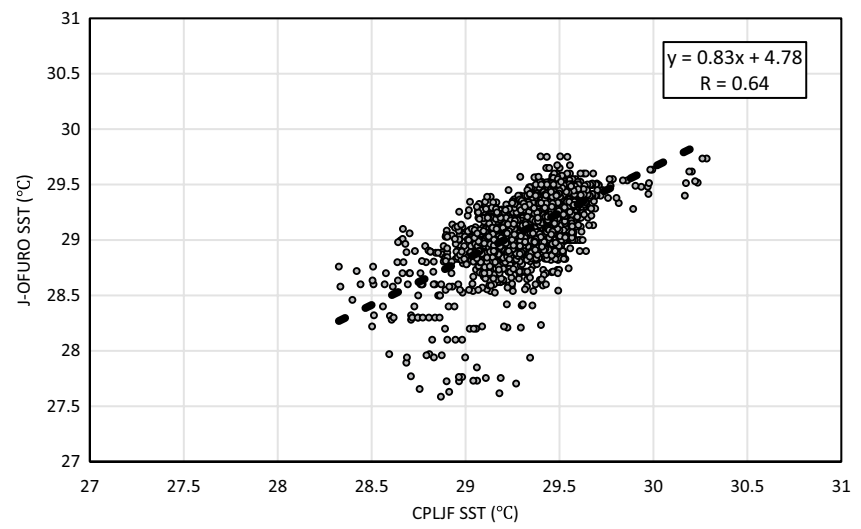

Fig. 9 The relationship of SST between J-OFURO3 data and simulation results. Scatter diagrams indicate the relationship. The dashed line in each panel indicates the linear correlation with the formula and correlation coefficient in the a CPLOI and $\mathbf{b}$ CPLJF experiments

(a)

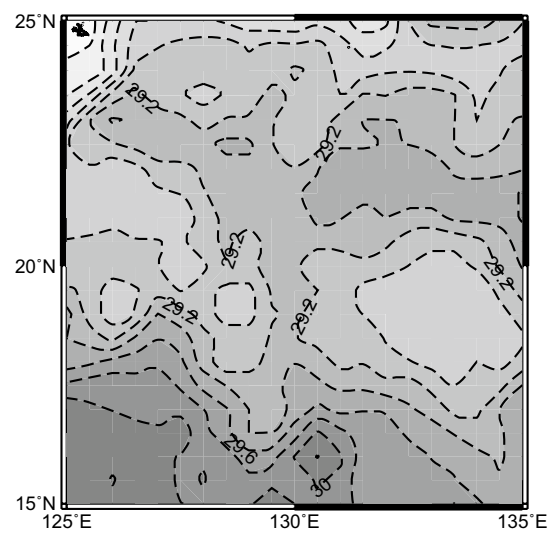

(b)

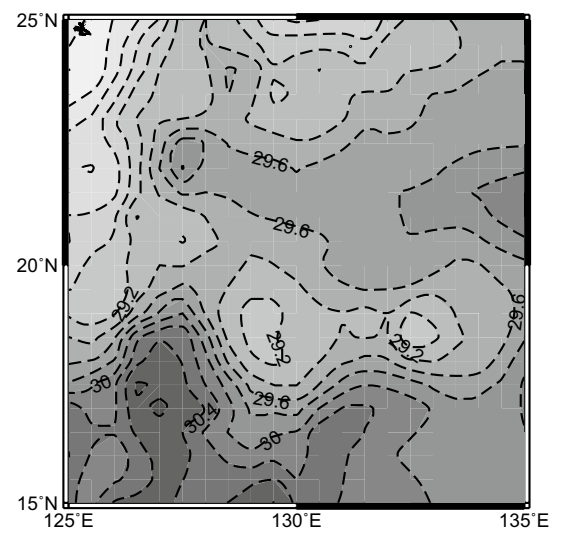

(c)

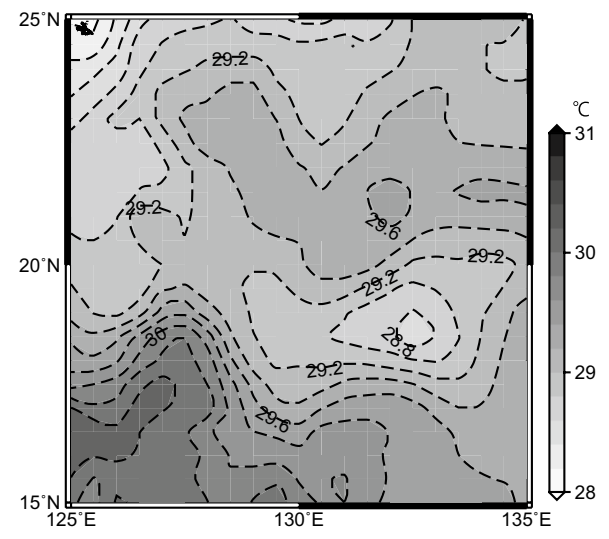

Fig. 10 Horizontal distribution of SST a in the J-OFURO3 data set, $\mathbf{b}$ in the CPLOI experiment and $\mathbf{c}$ in the CPLJF experiment. The $\mathrm{J}$-OFURO3 data set is a daily product, while the simulation results are the average from 12:00 UTC September 24 to 06:00 UTC September 25. The contour interval is $0.2{ }^{\circ} \mathrm{C}$

of $2 \mathrm{~m}$ air temperature is significant with the $t$ values of 37.9 (CPLOI), and 36.4 (CPLJF), corresponding to the $t$ test 99\% significant level (Fig. 11). The correlation coefficient in the OISST experiment is a little higher than that in the J-OFURO3 experiment. The overall $2 \mathrm{~m}$ air temperature in the J-OFURO3 data set is relatively high, whereas $2 \mathrm{~m}$ air temperature is low, and surface wind speed is high in the CPLOI, and CPLJF experiments (Fig. 12). In Fig. 12b, c, we can find that relatively warm air is spirally transported ahead of the moving TC toward the TC center on the northern side of the TC center due to frictional convergence.

The scatter diagram for $2 \mathrm{~m}$ specific humidity has different characteristics to the other physical components (Fig. 13), although the correlation is significant with $t$ values of 23.0 (CPLOI) and 27.6 (CPLJF), corresponding to the $t$ test $99 \%$ significant level. Overall, $2 \mathrm{~m}$ specific rather than within the inner core of a TC. The correlation 
(a)

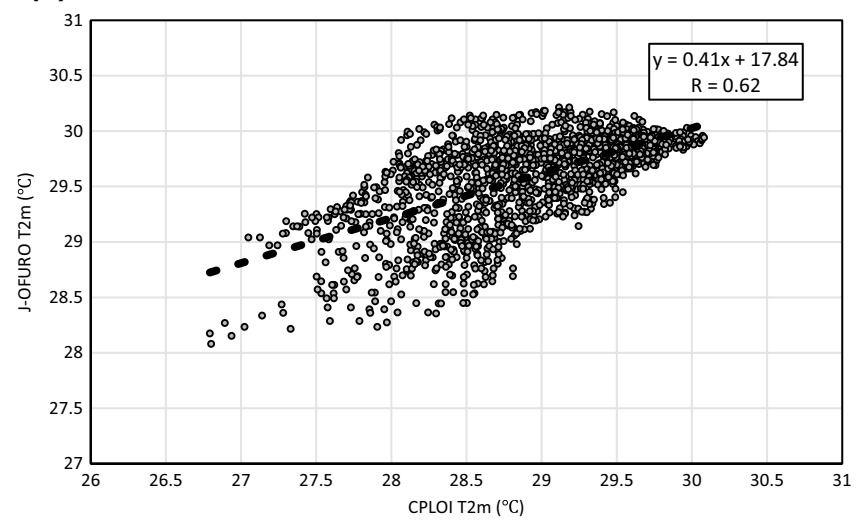

Fig. 11 The relationship of air temperature at the $2 \mathrm{~m}$ height between J-OFURO3 data and simulation results. Scatter diagrams indicate the relationship. The dashed line in each panel indicates the linear corre- (b)

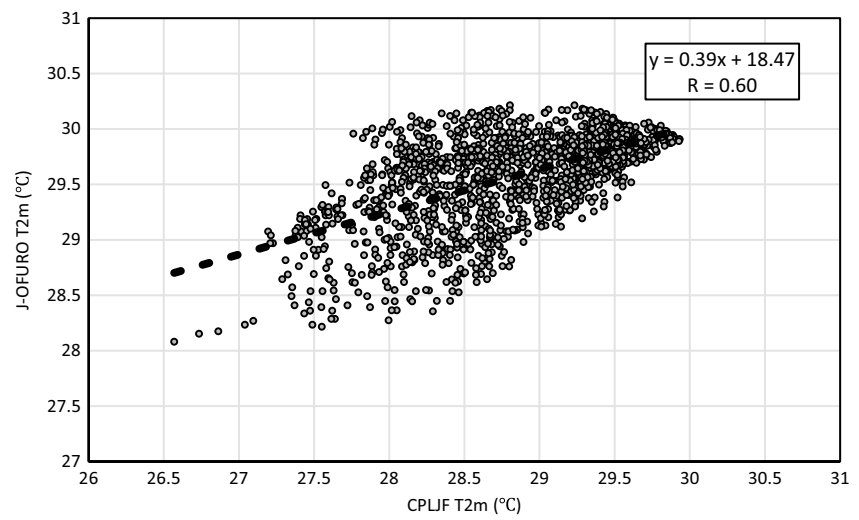

lation with the formula and correlation coefficient in the a CPLOI and b CPLJF experiments (a)

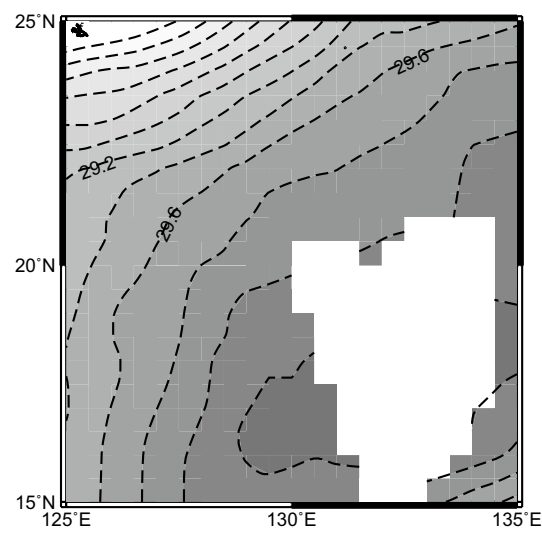

(b)

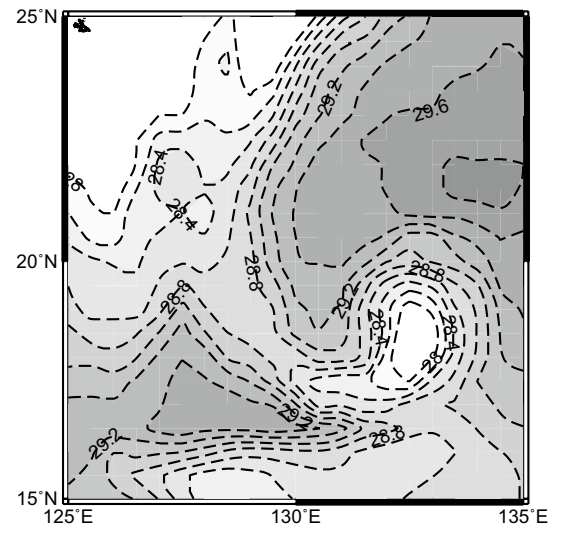

(c)

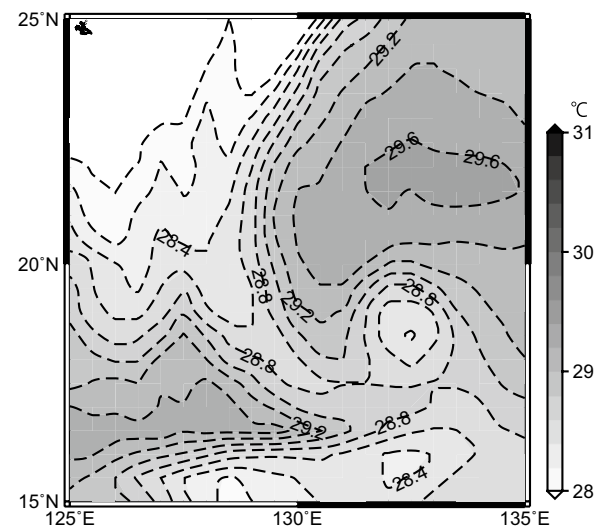

Fig. 12 Horizontal distribution of air temperature at the $2 \mathrm{~m}$ height $\mathbf{a}$ in the J-OFURO3 data set, $\mathbf{b}$ in the CPLOI experiment and $\mathbf{c}$ in the CPLJF experiment. The J-OFURO3 data set is a daily product, while

humidity in the J-OFURO3 data set is lower than that of the simulation results. Like the result of simulated $2 \mathrm{~m}$ air temperature, relatively moist air is spirally transported ahead of the moving TC toward the TC center on the northern side of the TC center due to frictional convergence (Fig. 14b, c). The frictional convergence of warm moist air plays a crucial role in TC intensification (e.g. Wada et al. 2018, Wada and Oyama 2018). However, 2 m specific humidity in the J-OFURO3 data set remains high at a saturated value of $21.5 \mathrm{~g} \mathrm{~kg}^{-1}$ on the northern side of the TC center, corresponding to the frictional-inflow area. In contrast, the simulated specific humidity is relatively low around the area of simulated accumulated precipitation from 12 UTC on September 24 to 06:00 UTC on September 25 in 2015 (Fig. 15). the simulation results are the average from 12 UTC 24 September to 06:00 UTC 25 September. The contour interval is $0.2{ }^{\circ} \mathrm{C}$. Missing values within the TC inner core are masked in white

Finally, the correlation between air-sea latent heat flux was investigated. The correlation is significant with the $t$ values of 27.5 (CPLOI) and 24.1 (CPLJF), corresponding to the $t$ test $99 \%$ significant level. Similar to the result of surface wind speed (Fig. 7), the air-sea latent heat flux in the J-OFURO3 data set is lower than that of simulation results, although the value of latent heat flux in the J-OFURO3 data set is higher than the simulated values when the simulated latent heat flux is lower than $300 \mathrm{~W} \mathrm{~m}^{-2}$ (Fig. 16). The high value is calculated outside the inner core of a TC (Fig. 17), and we must be aware that a high value of air-sea latent heat flux within the inner core of a TC cannot be evaluated in this study, even if a high value is seen in the J-OFURO3 data set.

It should be noted that the surface-specific humidity in the J-OFURO3 data set is missing data within 
(a)

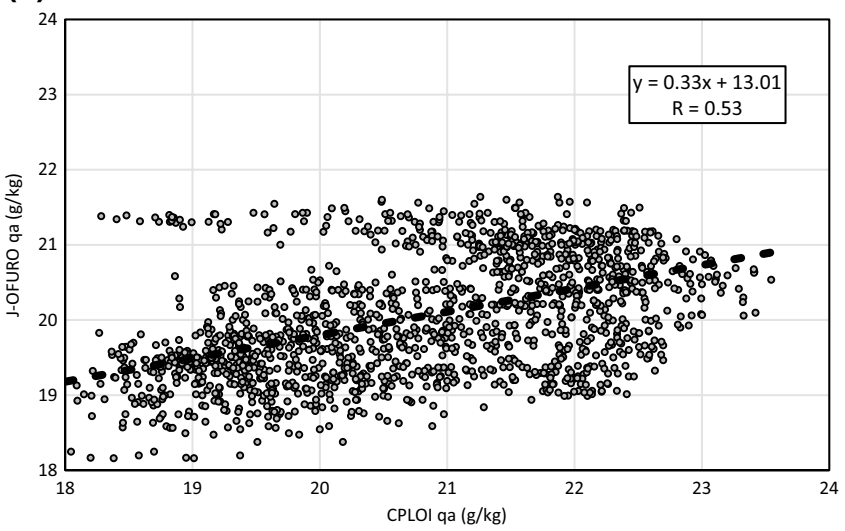

Fig. 13 The relationship of specific humidity at the $2 \mathrm{~m}$ height between J-OFURO3 data and simulation results. Scatter diagrams indicate the relationship. The dashed line in each panel indicates the (b)

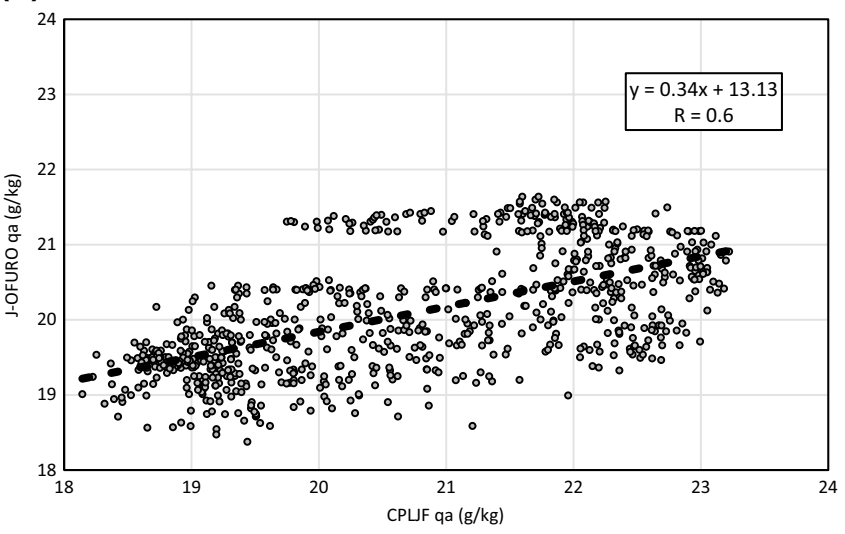

linear correlation with the formula and correlation coefficient in the a CPLOI and $\mathbf{b}$ CPLJF experiments (a)

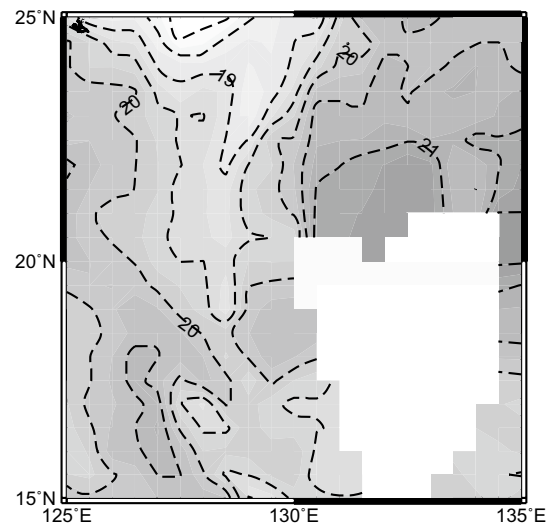

(b)

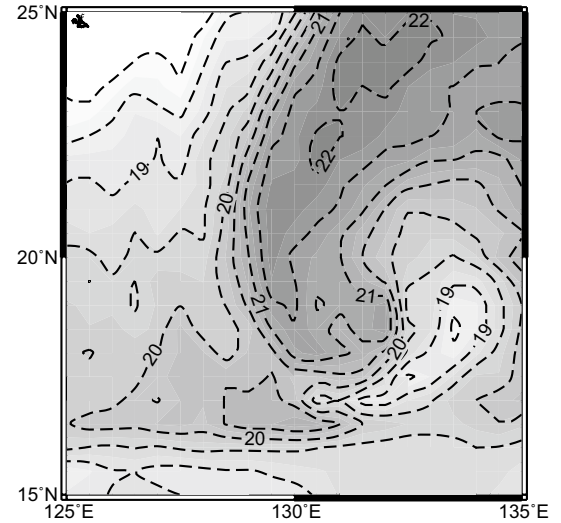

(c)

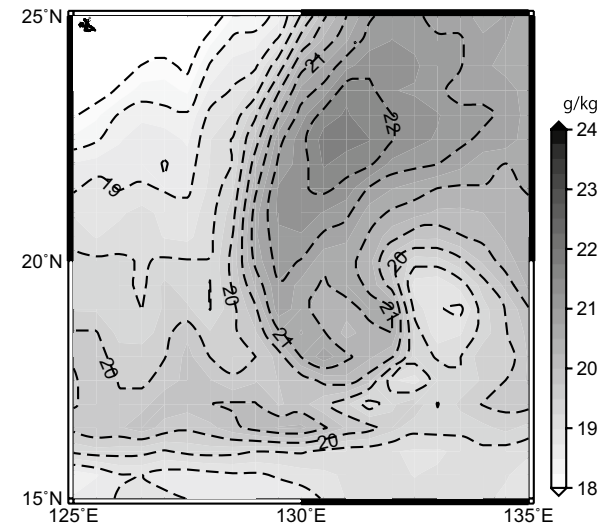

Fig. 14 Horizontal distribution of specific humidity at the $2 \mathrm{~m}$ height $\mathbf{a}$ in the J-OFURO3 data set, $\mathbf{b}$ in the CPLOI experiment and $\mathbf{c}$ in the CPLJF experiment. The J-OFURO3 data set is a daily product, while the simulation results are the average from 12:00 UTC September 24 to 06:00 UTC September 25. The contour interval is $0.5 \mathrm{~g} \mathrm{~kg}^{-1}$. Missing values within the TC inner core are masked in white
Fig. 15 Horizontal distribution of accumulated precipitation from 12 UTC 24 September to 06:00 UTC 25 September a in the CPLOI experiment and $\mathbf{b}$ in the CPLJF experiment. The contour interval is $50 \mathrm{~mm}$ (a)

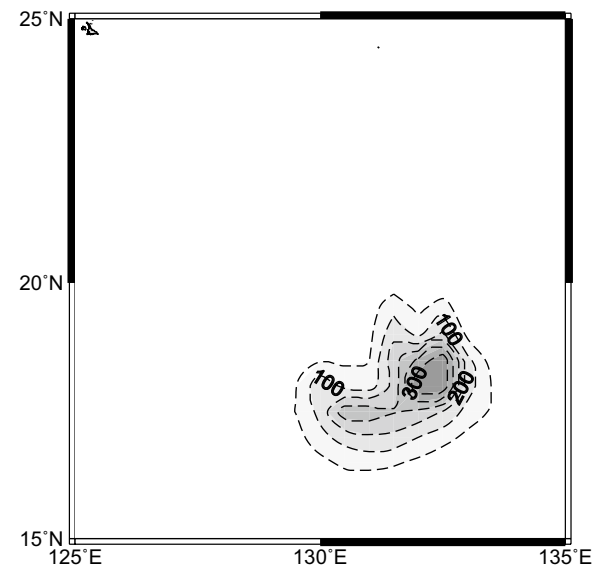

(b)

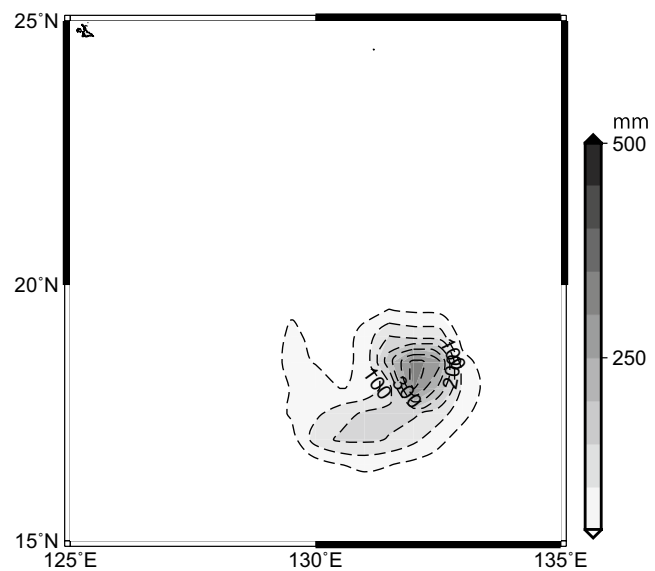


(a)

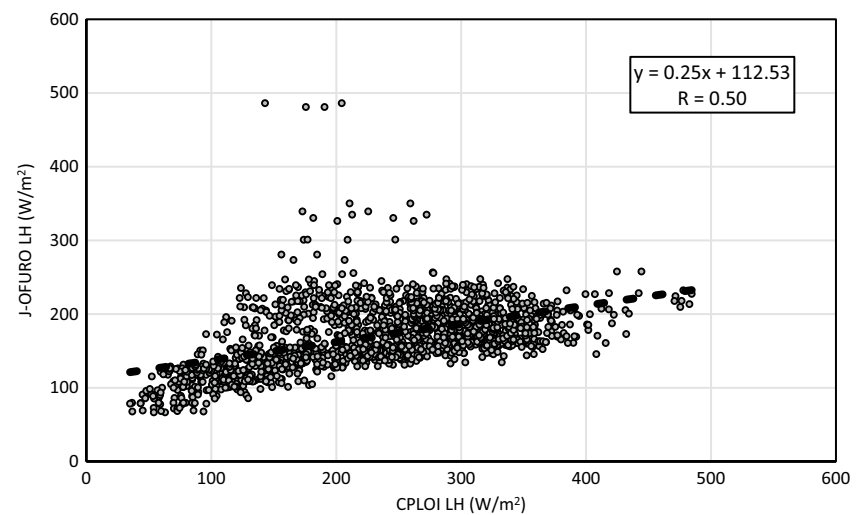

Fig. 16 The relationship of air-sea latent heat flux between J-OFURO3 data and simulation results. Scatter diagrams indicate the relationship. The dashed line in each panel indicates the linear corre- (b)

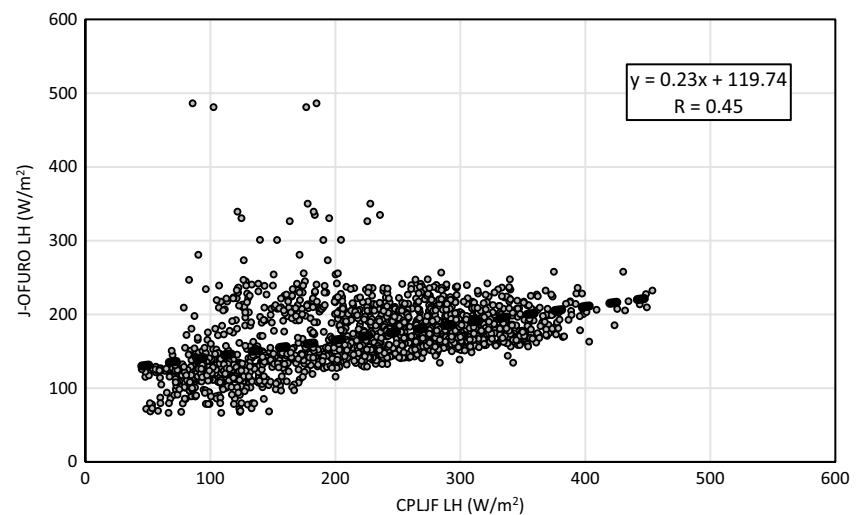

lation with the formula and correlation coefficient in the a CPLOI and b CPLJF experiments (a)

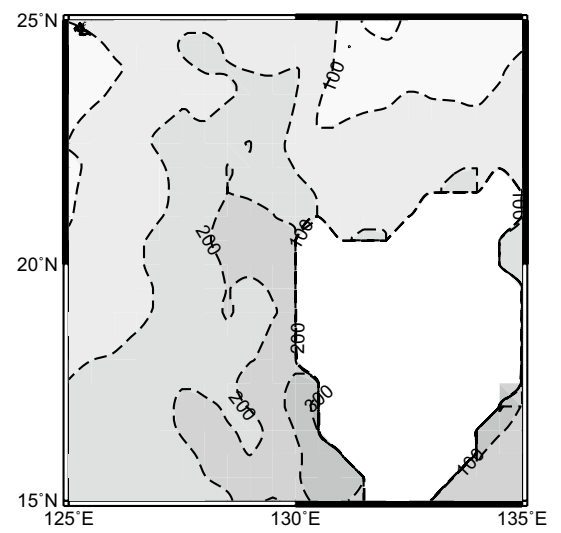

(b)

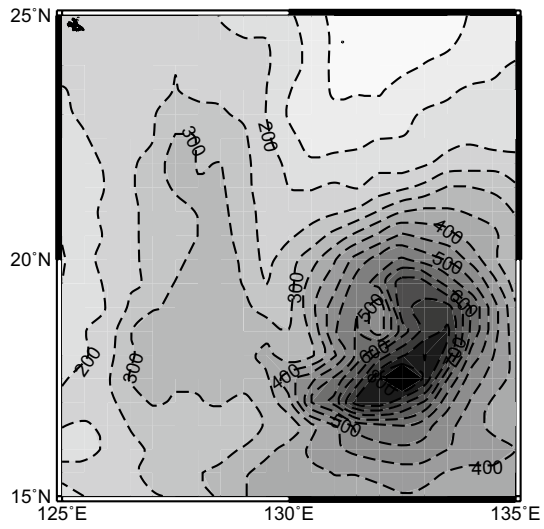

(c)

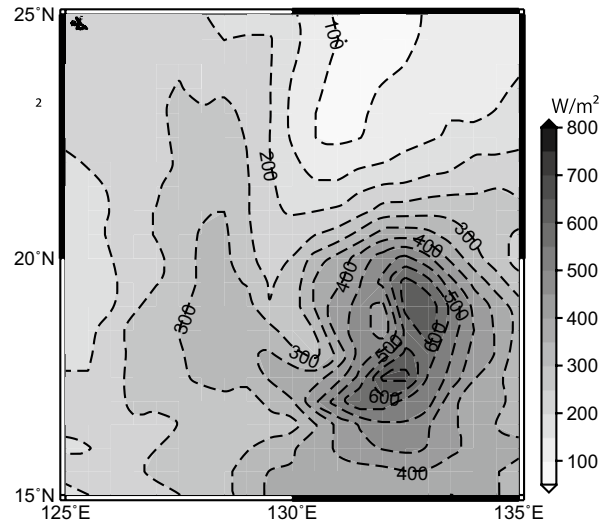

Fig. 17 Horizontal distribution of specific humidity at the $2 \mathrm{~m}$ height $\mathbf{a}$ in the J-OFURO3 data set, $\mathbf{b}$ in the CPLOI experiment and $\mathbf{c}$ in the CPLJF experiment. The J-OFURO3 data set is a daily product, while the simulation results are the average from 12:00 UTC September 24 to 06:00 UTC September 25. The contour interval is $100 \mathrm{~W} \mathrm{~m}^{-2}$. Missing values within the TC inner core are masked in white the inner core of TCs due to an issue with the satellite estimation algorithm. The algorithm used in J-OFURO3 cannot retrieve surface specific humidity in heavy rain conditions such as during a TC because the brightness temperature observed by satellite microwave radiometer is mostly influenced by rain rather than humidity. For the surface temperature estimation, the air-sea flux estimation algorithm is affected by atmospheric stability, and therefore, even if reanalysis surface temperature data exists within the inner core of TCs, the output data tend to be missing data because there are no surfacespecific humidity data. This will be discussed in the next section.

\section{Discussion}

\subsection{Model dependency}

In this study, we used only one numerical model and compared the simulation results and J-OFURO3 data only for a limited analysis area. Recent studies have suggested that the inner-core structure of a TC differs depending on the model used (Kanada et al. 2017; Nakano et al. 2017). Even in the same numerical model, it was reported that the relationship between the central pressure and MSW differs by changing the atmospheric boundary-layer process and cloud physics (Chen et al. 2019). In contrast, the impact of the effect of ocean coupling on the inner-core structural change is relatively small (Wada et al. 2018). 
Apart from the variety within the inner-core structure of simulated TCs, J-OFURO3 data are useful only for representing the inner-core structure of a real TC. They serve as a testbed to determine which numerical model realistically reproduces the inner-core structure of a real TC. Such intercomparison, and the associated improvement of model physics, will be able to contribute to the improvement of TC intensity prediction by the numerical model. These are important issues for future research.

\subsection{MSW}

Statistically, the MSW in the J-OFURO3 data set has a linear relationship with that of RSMC Tokyo best track data. In addition, the value of the slope in Fig. 2a shows that the MSW in the J-OFURO3 data set is lower than that of the RSMC Tokyo best track data. The slope difference between Fig. 2a, $\mathrm{b}$ is significant, with the $t$ values of 3.78 , corresponding to the $t$ test 99\% significant level. Moreover, Fig. 7 demonstrates that the surface wind speed in the J-OFURO3 data set is underestimated compared with the two numerical simulation

(a)

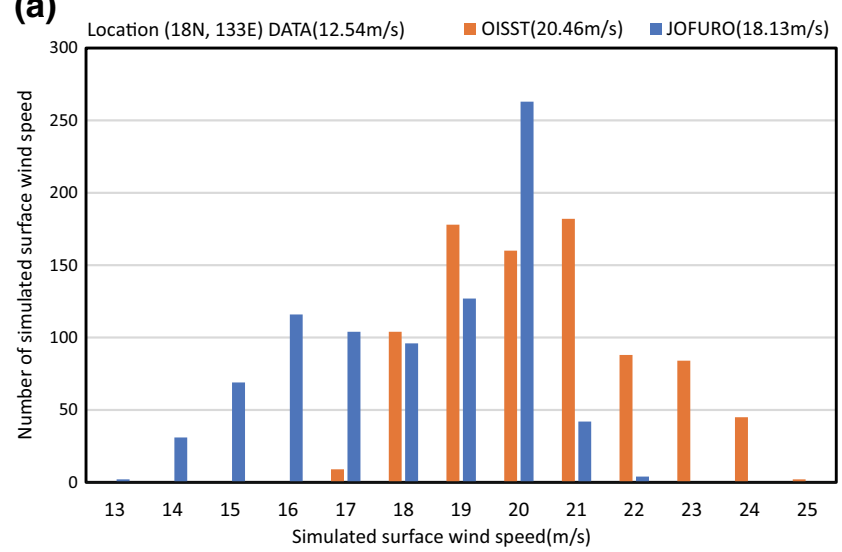

(c)

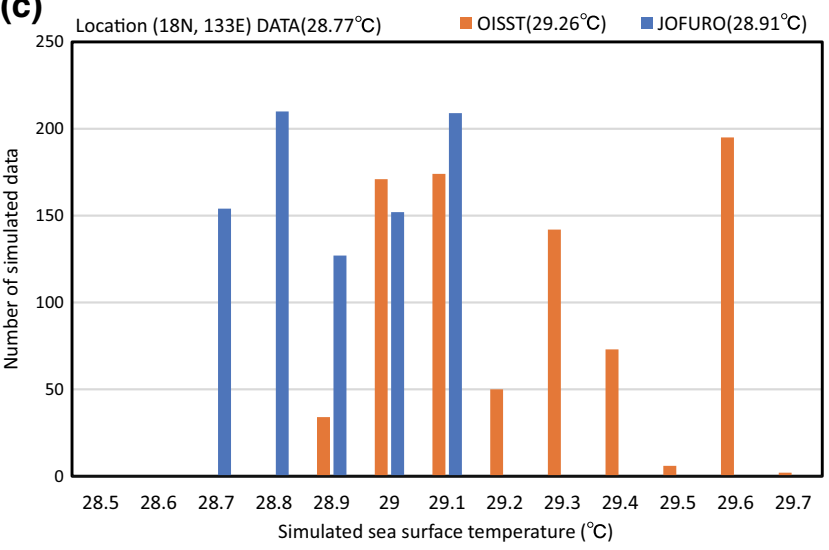

Fig. 18 Histograms of simulated surface wind speeds in the CPLOI (orange) and CPLJF (blue) experiments from 12:00 UTC September 24 to $06: 00$ UTC 25 September a at $18^{\circ} \mathrm{N}, 133^{\circ} \mathrm{E}$ and $\mathbf{b}$ at $20^{\circ} \mathrm{N}$, results in the range of $10 \mathrm{~m} \mathrm{~s}^{-1}$ or less and $20 \mathrm{~m} \mathrm{~s}^{-1}$ or more. One of the factors causing underestimation is that numerical simulations with a horizontal resolution of $2 \mathrm{~km}$ can express small fluctuations in surface wind speeds caused by physical processes with finer spatial, and temporal scales than those of J-OFURO3 $\left(0.25^{\circ}\right.$ and a day). Figure 18 displays histograms of simulated surface wind speeds and simulated SST at $18^{\circ}$ $\mathrm{N}, 133^{\circ} \mathrm{E}$ and at $20^{\circ} \mathrm{N}, 130^{\circ} \mathrm{E}$ from 12:00 UTC September 24 to 06:00 UTC September 25. The simulation results include various values for one grid point of the J-OFURO3 data set. The spread of the simulated value is larger at $18^{\circ} \mathrm{N}$, $133^{\circ} \mathrm{E}$ (Fig. 18a, c), which corresponds to the area during, and after the passage of TC, than at $20^{\circ} \mathrm{N}, 130^{\circ} \mathrm{E}$ (Fig. 18b, $\mathrm{d})$. The range of the spread is larger in the simulated surface wind speed (Fig. 18a, b) than in the simulated SST (Fig. 18c, d). These results suggest the existence of small fluctuations in simulated surface wind speeds, which cannot be analyzed in the J-OFURO3 data set.

In contrast, the slope of the linear correlation function indicated that the MSW in the JRA-55 data set corresponds to that of the RSMC Tokyo best track. This is because an

(b)

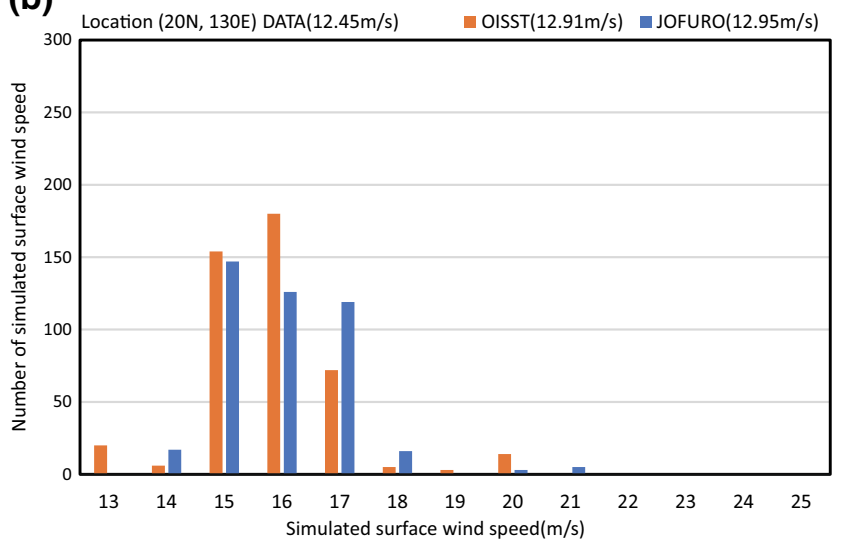

(d)

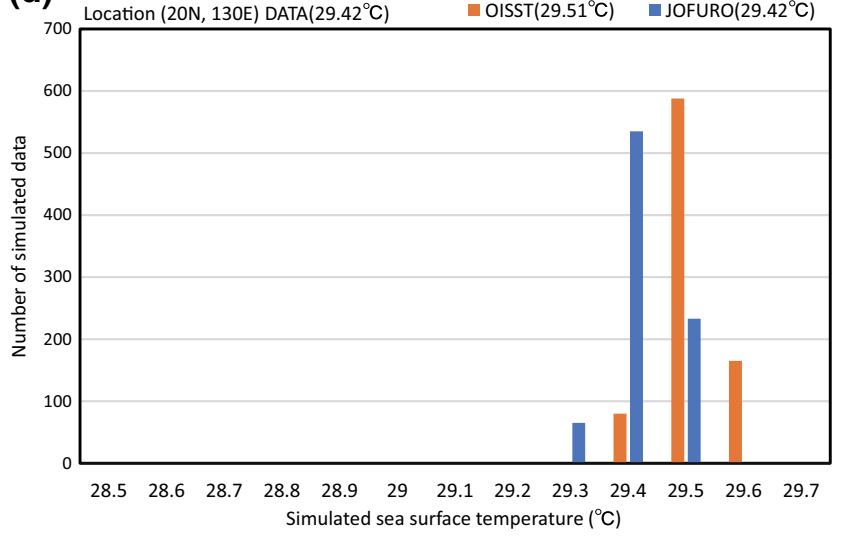

$130^{\circ} \mathrm{E}$ and those of simulated SST $\mathbf{c}$ at $18^{\circ} \mathrm{N}, 133^{\circ} \mathrm{E}$ and $\mathbf{d}$ at $20^{\circ} \mathrm{N}$, $130^{\circ} \mathrm{E}$. The number in the legend next to the title indicates the average value (color figure online) 
artificial vortex (TC bogus) was embedded into the 'guess' analysis field every cycle $(6 \mathrm{~h})$ when a TC existed. Therefore, the MSW cannot be quantitatively reproduced in the J-OFURO3 data set, although the J-OFURO3 dataset was excellent for expressing the wind distribution within the inner core of a TC.

Most of the satellite retrieved surface wind speed data used in the J-OFURO3 data set have problems measuring surface wind speeds of $35 \mathrm{~m} \mathrm{~s}^{-1}$ or more (Bourassa et al. 2019). In addition to heavy rainfall within the inner core of a TC, the effects of air-sea interfacial processes such as breaking waves and whitecapping on the surface wind speed are not fully understood (Zabolotskikh et al. 2014). Recently, Synthetic Aperture Radar (SAR) missions (Bourassa et al. 2019), and the Cyclone Global Navigation Satellite Systems (CYGNSS) constellation of eight small microsatellites (Morris and Ruf 2017) developed the surface wind speed measurement up to $75 \mathrm{~m} \mathrm{~s}^{-1}$. As a climate data set, it is conceivable that the uniformity of data over a long period may be impaired. Tomita et al. (2019) have pointed out that the number and type of satellite sensors that J-OFURO3 uses differs from year to year, making it difficult to achieve a long-term uniform dataset. The use of high-accuracy surface wind data may it more difficult to compile uniform climate data.

\subsection{Temperature and specific humidity within a TC}

Atmospheric reanalysis data such as ECMWF reanalysis interim and NRA2 are used to estimate near-surface air temperature and specific humidity in the J-OFURO3 data set, respectively (Tomita et al. 2019). Atmospheric reanalysis data is utilized to estimate near-surface air temperature, and specific humidity, not only in the J-OFURO3 data set but also in many air-sea latent heat flux products estimated by satellite observations (Crespo et al. 2019; Gao et al. 2019). One of the remarkable differences between the J-OFURO3 data set and these products is the specific humidity estimation method (Tomita et al. 2018). To the authors' knowledge, there is little research on estimation methods that do not utilize atmospheric reanalysis data, aside from a study on near-surface air temperature and specific humidity estimates using multisensor microwave satellite observations (Jackson et al. 2006, 2009). There is no research regarding estimating near-surface air temperature and specific humidity, particularly within the inner core of a TC with or without utilizing atmospheric reanalysis data.

In Figs. 12 and 14, both the near-surface air temperature and specific humidity are seen to be relatively low over the area where the simulated accumulated precipitation is high (Fig. 15). The lowering indicates that surface cold pools are formed over the high-precipitation area in the simulation results, resulting from evaporatively cooled downdraft air that has spread out beneath a precipitating cloud (Eastin et al. 2012). The simulated air-sea latent heat flux is thus relatively high over the high-precipitation area because of the differences in temperature and specific humidity between the atmosphere and the ocean increase. By quantitatively evaluating the relationship between cold pool formation due to precipitation and the decrease in near-surface air temperature and specific humidity within the inner core of TCs, it will be possible to estimate air temperature and specific humidity there. Although the development of the method is beyond the scope of this study, future development is expected.

\section{Concluding remarks}

To investigate the extent to which the third generation Japanese Ocean Flux Data Sets with Use of Remote-Sensing Observations (J-OFURO3) is available for tropical cyclone research, this study compared the J-OFURO3 data with the Regional Specialized Meteorological Center (RSMC) Tokyo best track data, the Japanese 55-year Reanalysis (JRA-55) 6-hourly atmospheric reanalysis data, the simulation results conducted by a $2 \mathrm{~km}$ mesh regional nonhydrostatic atmosphere model (NHM), and the atmosphere-wave-ocean coupled model (CPM).

The climatological characteristics of TCs were first investigated by using the J-OFURO3 data set. During 1996-2015, the amplitude of TC-induced sea surface cooling became high south of Okinawa at approximately $20^{\circ} \mathrm{N}, 130^{\circ} \mathrm{E}$. The result is consistent with the time trend of RSMC Tokyo best track central pressure over the area. With regards to the maximum wind speed (MWS), the correlation between the J-OFURO3 data and the RSMC Tokyo best track data was consistent with that of the JRA-55 data. The asymmetrical distribution of surface wind speeds within the inner core of a TC can be analyzed well in the J-OFURO3 data set to the same extent as the simulation results by the CPM. In contrast, the JRA-55 data cannot analyze the asymmetry of surface wind speed due to the relatively coarse resolution $\left(1.25^{\circ}\right)$.

Atmospheric and oceanic components such as surface wind speed and sea surface temperature (SST) in the J-OFURO3 data set were significantly correlated with the simulation results. There is, however, room for improvement for constructing atmospheric, and oceanic components such as $2 \mathrm{~m}$ air temperature, $2 \mathrm{~m}$ specific humidity, and airsea latent heat flux within the inner core of a TC, although they are significantly correlated with the simulation results. Although this study is only one case analysis with a limited study area, this study demonstrates that the J-OFURO3 data set is useful for TC climatology studies.

In the J-OFURO3 data set, TC-induced sea surface cooling was well analyzed and was comparable with the simulation results. Although SST at the initial time affected the accuracy of the simulated SST, the simulations of the 
surface wind speed, $2 \mathrm{~m}$ air temperature, and $2 \mathrm{~m}$ specific humidity were still inconsistent with the J-OFURO3 data set, although simulated SST was more accurate. Future investigations should be conducted by increasing the number of comparison cases and numerical simulations and focusing on other study areas. In addition, the surface air temperature and specific humidity data within the inner core of a TC will be enriched in the next generation J-OFURO data set. To improve the inconsistency between the simulations and J-OFURO3 data set, both new algorisms and more satellite data used are expected for accurately deriving $2 \mathrm{~m}$ air temperature, $2 \mathrm{~m}$ specific humidity, and air-sea latent heat flux data within the TC inner core in the J-OFURO3 data set. Moreover, there is room for improvement in the physical processes in the NHM because the NHM used in this study cannot reproduce the variation in observed air temperature even in the atmosphere-ocean coupled assimilation system (Fig. 11 in Wada and Kunii 2017). This will lead to an improvement of air-sea surface fluxes within the inner core of a TC.

Acknowledgements The authors are grateful for two anonymous reviewers for their comments that help to improve the manuscript. This study was supported by the Japan Society for the Promotion of Science Grants-in-Aid for Scientific Research (KAKENHI) Grant Numbers JP18H03737 and JP19H05696.

Open Access This article is licensed under a Creative Commons Attribution 4.0 International License, which permits use, sharing, adaptation, distribution and reproduction in any medium or format, as long as you give appropriate credit to the original author(s) and the source, provide a link to the Creative Commons licence, and indicate if changes were made. The images or other third party material in this article are included in the article's Creative Commons licence, unless indicated otherwise in a credit line to the material. If material is not included in the article's Creative Commons licence and your intended use is not permitted by statutory regulation or exceeds the permitted use, you will need to obtain permission directly from the copyright holder. To view a copy of this licence, visit http://creativecommons.org/licenses/by/4.0/.

\section{References}

Bender MA, Ginis I, Kurihara Y (1993) Numerical simulations of tropical cyclone-ocean interaction with a high-resolution coupled model. J Geophys Res Atmos 98:23245-23263. https://doi. org/10.1029/93JD02370

Bourassa MA, Meissner T, Cerovecki I, Chang PS, Dong X, De Chiara G, Donlon C, Dukhovskoy DS, Elya J, Fore A, Fewings MR, Foster RC, Gille ST, Haus BK, Hristova-Veleva S, Holbach HM, Jelenak Z, Knaff JA, Kranz SA, Manaster A, Mazloff M, Mears C, Mouche A, Portabella M, Reul N, Ricciardulli L, Rodriguez E, Sampson C, Solis D, Stoffelen A, Stukel MR, Stiles B, Weissman D, Wentz F (2019) Remotely sensed winds and wind stresses for marine forecasting and ocean modeling. Front Mar Sci 6:443. https://doi.org/10.3389/fmars.2019.00443

Chen SS, Price JF, Zhao W, Donelan MA, Walsh EJ (2007) The CBLAST-Hurricane program and the next generation fully coupled atmosphere-wave-ocean models for hurricane research and prediction. Bull Am Meteorol Soc 88:311-317. https://doi. org/10.1175/BAMS-88-3-31111

Chen J-H, Lin S-J, Magnusson L, Bender M, Chen X, Zhou L, Xiang B, Rees S, Morin M, Harris L (2019) Advancements in hurricane prediction with NOAA's next-generation forecast system. Geophys Res Lett 46:4495-4501. https://doi.org/10.1029/2019G L082410

Crespo JA, Posselt DJ, Asharaf S (2019) CYGNSS surface heat flux product development. Remote Sens 11:2294. https://doi. org/10.3390/rs 11192294

D’Asaro E, Black P, Centurioni L, Harr P, Jayne S, Lin I-I, Lee C, Morzel J, Mrvaljevic R, Niiler P, Sanford T, Tang T (2011) Typhoonocean interaction in the western North Pacific: part 1. Oceanography 24:24-31. https://doi.org/10.5670/oceanog.2011.91

Dare RA, McBride JL (2011) The threshold sea surface temperature condition for tropical cyclogenesis. J Clim 24:4570-4576. https ://doi.org/10.1175/JCLI-D-10-05006.1

Deardorff JW (1980) Stratocumulus-capped mixed layers derived from a three-dimensional model. Bound Layer Meteorol 18:495-527. https://doi.org/10.1007/BF00119502

Deardorff JW (1983) A multi-limit mixed-layer entrainment formulation. J Phys Oceanogr 13:988-1002. https://doi. org/10.1175/1520-0485(1983)013<0988:AMLMLE > 2.0.CO;2

Dee DP, Uppala SM, Simmons AJ et al (2011) The ERA-Interim reanalysis: configuration and performance of the data assimilation system. Q J R Meteorol Soc 137(656):553-597. https://doi. org/10.1002/qj. 828

Eastin MD, Gardner TL, Link MC, Smith KC (2012) Surface cold pools in the outer rainbands of tropical storm Hanna (2008) near landfall. Mon Wea Rev 140:471-491. https://doi.org/10.1175/ MWR-D-11-00099.1

Emanuel KA (1986) An air-sea interaction theory for tropical cyclones. 1 Steady-state maintenance. J Atmos Sci 43:1763-1775. https:// doi.org/10.1175/1520-0469(1986)043<0585:AASITF>2.0.CO;2

Evans JL (1993) Sensitivity of tropical cyclone intensity to sea surface temperature. J Clim 6:1133-1140. https://doi.org/10.1175/15200442(1993)006<1133:SOTCIT>2.0.CO;2

Fairall CW, Bradley EF, Hare JE, Grachev AA, Edson JB (2003) Bulk parameterization of air-sea fluxes: updates and verification for the COARE algorithm. J Clim 16(4):571-591

Gao Q, Wang S, Yang X (2019) Estimation of surface air specific humidity and air-sea latent heat flux using FY-3C microwave observations. Remote Sens 11:466. https://doi.org/10.3390/rs110 40466

Ikawa M, Saito K (1991) Description of a nonhydrostatic model developed at the forecast research department of the MRI. Tech Rep Meteorol Res Inst 28:238. https://doi.org/10.11483/mritechrep o. 28

Jackson DL, Wick GA, Bates JJ (2006) Near-surface retrieval of air temperature and specific humidity using multisensor microwave satellite observations. J Geophys Res 111:D10306. https://doi. org/10.1029/2005JD006431

Jackson DL, Wick GA, Robertson FR (2009) Improved multisensor approach to satellite-retrieved near-surface specific humidity observations. J Geophys Res 114:D16303. https://doi. org/10.1029/2008JD011341

Japan Meteorological Agency (2013). Outline of the operational numerical weather prediction at the Japan Meteorological Agency. Appendix to WMO technical progress report on the Global DataProcessing and Forecasting System (GDPFS) and Numerical Weather Prediction (NWP) research, March, 2013. Japan Meteorological Agency, Tokyo, p 188

Kanada S, Takemi T, Kato M, Yamasaki S, Fudeyasu H, Tsuboki K, Arakawa O, Takayabu I (2017) A multimodel intercomparison of an intense typhoon in future, warmer climates by four $5-\mathrm{km}-\mathrm{mesh}$ 
models. J Climate 30:6017-6036. https://doi.org/10.1175/ JCLI-D-16-0715.1

Kanamitsu M, Ebisuzaki W, Woollen J, Yang SK, Hnilo JJ, Fiorino M, Potter GL (2002) NCEP-DOE AMIP-II reanalysis (R-2). Bull Am Meteorol Soc 83:1631-1643. https://doi.org/10.1175/ BAMS-83-11-1631

Kawai Y, Wada A (2007) Diurnal sea surface temperature variation and its impact on the atmosphere and ocean: a review. J Oceanogr 63:721-744. https://doi.org/10.1007/s10872-007-0063-0

Klemp JB, Wilhelmson R (1978) The simulation of three-dimensional convective storm dynamics. J Atmos Sci 35:1070-1096. https:// doi.org/10.1175/1520-0469(1978)035<1070:TSOTDC >2.0.CO;2

Koba H, Hagiwara T, Osano S, Akashi S (1990) Relationships between CI Number from Dvorak's technique and minimum sea level pressure or maximum speed of tropical cyclone. J Meteor Res 42:59-67 (in Japanese)

Kobayashi S, Ota Y, Harada Y, Ebita A, Moriya M, Onoda H, Onogi K, Kamahori H, Kobayashi C, Endo H, Miyaoka K, Takahashi K (2015) The JRA-55 reanalysis: general specifications and basic characteristics. J Meteor Soc Japan 93:5-48. https://doi. org/10.2151/jmsj.2015-001

Kondo J (1975) Air-sea bulk transfer coefficients in diabatic conditions. Bound Layer Meteorol 9:91-112. https://doi.org/10.1007/ BF00232256

Kurihara Y, Sakurai T, Kuragano T (2006) Global daily sea surface temperature analysis using data from satellite microwave radiometer, satellite infrared radiometer and in situ observations. Weather Service Bull. 73 (special issue), Japan Meteorological Agency, 1-18 (in Japanese). Accessed June 10

Lin YH, Farley RD, Orville HD (1983) Bulk parameterization of the snowfield in a cloud model. J Clim Appl Meteorol 22:1065-1092. https://doi.org/10.1175/1520-0450(1983)022<1065:BPOTS $\mathrm{F}>2.0 . \mathrm{CO} ; 2$

Lin I-I, Timothy Liu W, Wu C-C, Chiang JCH, Sui CH (2003) Satellite observations of modulation of surface winds by typhooninduced upper ocean cooling. Geophys Res Lett 30:1131. https:// doi.org/10.1029/2002GL015674

Lin I-I, Wu C-C, Emanuel KA, Lee I, Wu C-R, Pun IF (2005) The interaction of Supertyphoon Maemi (2003) with a Warm Ocean Eddy. Mon Wea Rev 133:2635-2649. https://doi.org/10.1175/ MWR3005.1

Manuel KA (1995) Sensitivity of tropical cyclones to surface exchange coefficients and a revised steady-state model incorporating eye dynamics. J Atmos Sci 52:3969-3976. https://doi. org/10.1175/1520-0469(1995)052<3969:SOTCTS > 2.0.CO;2

Monaldo FM, Sikora TD, Babin SM, Sterner RE (1997) Satellite imagery of sea surface temperature cooling in the wake of Hurricane Edouard (1996). Mon Wea Rev 125:2716-2721. https:// doi.org/10.1175/1520-0493(1997)125<2716:SIOSST>2.0.CO;2

Mori K, Ishigaki S, Maehira T, Ohya M, Takeuchi H (1999) Structure and evolution of convection within typhoon Yancy (T9313) in the early developing stage observed by the Keifu Maru Radar. J Meteor Soc Japan 77:459-482. https://doi.org/10.2151/jmsj1 965.77 .2459

Morris M, Ruf CS (2017) Determining tropical cyclone surface wind speed structure and intensity with the CYGNSS satellite constellation. J Appl Meteor Climatol 56:1847-1865. https://doi. org/10.1175/JAMC-D-16-0375.1

Nakano M, Wada A, Sawada M, Yoshimura H, Onishi R, Kawahara S, Sasaki W, Nasuno T, Yamaguchi M, Iriguchi T, Sugi M (2017) Takeuchi Y (2017) Global 7 km mesh nonhydrostatic Model Intercomparison Project for improving TYphoon forecast (TYMIPG7): experimental design and preliminary results. Geosci Model Dev 10:1363-1381. https://doi.org/10.5194/gmd-10-1363-2017

Oyama R, Wada A (2019) The relationship between convective bursts and warm-core intensification in a nonhydrostatic simulation of
Typhoon Lionrock (2016). Mon Wea Rev 147:1557-1579. https ://doi.org/10.1175/MWR-D-18-0457.1

Palmen E (1948) On the formation and structure of tropical hurricanes. Geophysica 3:26-38

Pun IF, Chang Y-T, Lin I-I, Tang TY, Lien R-C (2011) Typhoon-ocean interaction in the western North Pacific: part 2. Oceanography 24:32-41. https://doi.org/10.5670/oceanog.2011.92

Qiu B (1999) Seasonal eddy field modulation of the North Pacific Subtropical Countercurrent: TOPEX/Poseidon observations and theory. J Phys Oceanogr 29:1670-1685. https://doi. org/10.1175/1520-0485(2001)031<0675:ETOHAT>2.0.CO;2

Saito K (2012) The JMA Nonhydrostatic model and its applications to operation and research. In: Yucel I (ed) Atmospheric Model Applications. InTech, Croatia, pp 85-110. https://doi. org/10.5772/35368

Shay LK, Goni GJ, Black PG (2000) Role of a warm ocean feature on Hurricane Opal. Mon Weather Rev 128:1366-1383. https://doi. org/10.1175/1520-0493(2000)128<1366:EOAWOF > 2.0.CO;2

Sugi M, Kuma K, Tada K, Tamiya K, Hasegawa N, Iwasaki T, Yamada S, Kitade T (1990) Description and performance of the JMA operational global spectral model (JMA-GSM88). Geophys Mag 43:105-130

Taylor PK, Yelland MJ (2001) The dependence of sea surface roughness on the height and steepness of the waves. J Phys Oceanogr 31:572-590. https://doi.org/10.1175/15200485(2001)031<0572:TDOSSR > 2.0.CO;2

Tomita H, Hihara T, Kubota M (2018) Improved satellite estimation of near-surface humidity using vertical water vapor profile information. Geophys Res Lett. https://doi.org/10.1002/2017GL076384

Tomita H, Hihara T, Kako S, Kubota M, Kutsuwada K (2019) An introduction to J-OFURO3, a third-generation Japanese ocean flux data set using remote-sensing observations. J Oceanogr 75:171-194. https://doi.org/10.1007/s10872-018-0493-x

Usui N, Wakamatsu T, Tanaka Y, Hirose N, Toyoda T, Nishikawa S, Fujii Y, Takatsuki Y, Igarashi H, Nishikawa H, Ishikawa Y, Kuragano T, Kamachi M (2017) Four-dimensional variational ocean reanalysis: a 30-year high-resolution dataset in the western North Pacific (FORA-WNP30). J Oceanogr 73:205-233. https://doi. org/10.1007/s10872-016-0398-5

Wada A (2005) Numerical simulations of sea surface cooling by a mixed layer model during the passage of Typhoon Rex. J Oceanogr 61:41-57. https://doi.org/10.1007/s10872-005-0018-2

Wada A (2019) The impacts of a cold eddy induced by Typhoon Trami (2018) on the intensity forecast of Typhoon Kong-Rey (2018). CAS/JSC WGNE Res Act Atm Ocean Model 49:9-07

Wada A, Kunii M (2017) The role of ocean-atmosphere interaction in Typhoon Sinlaku (2008) using a regional coupled data assimilation system. J Geophys Res Oceans 122:3675-3695. https://doi. org/10.1002/2017JC012750

Wada A, Oyama R (2018) Relation of convective bursts to changes in the intensity of Typhoon Lionrock (2016) during the decay phase simulated by an atmosphere-wave-ocean coupled model. J Meteor Soc Japan 96:489-509. https://doi.org/10.2151/jmsj.2018-052

Wada A, Usui N (2007) Importance of tropical cyclone heat potential for tropical cyclone intensity and intensification in the Western North Pacific. J Oceanogr 63:427-447. https://doi.org/10.1007/ s10872-007-0039-0

Wada A, Kohno M, Kawai Y (2010) Impact of wave-ocean interaction on typhoon Hai-Tang in 2005. SOLA 6A:13-16. https://doi. org/10.2151/sola.6A-004

Wada A, Cronin MF, Sutton AJ, Kawai Y, Ishii M (2013) Numerical simulations of oceanic $p \mathrm{CO}_{2}$ variations and interactions between Typhoon Choi-wan (0914) and the ocean. J Geophys Res Ocean 118:2667-2684. https://doi.org/10.1002/jgrc.20203

Wada A, Kanada S, Yamada H (2018) Effect of air-sea environmental conditions and interfacial processes on extremely intense typhoon 
Haiyan (2013). J Geophys Res Atmos 123:10379-10405. https:// doi.org/10.1029/2017JD028139

Wu C-C, Lee C-Y, Lin I-I (2007) The effect of the ocean eddy on tropical cyclone intensity. J Atmos Sci 64:3562-3578. https://doi. org/10.1175/JAS4051.1
Zabolotskikh E, Mitnik L, Chapron B (2014) GCOM-W1 AMSR2 and MetOp-A ASCAT wind speeds for the extratropical cyclones over the North Atlantic. Remote Sens Environ 147:89-98. https://doi. org/10.1016/j.rse.2014.02.016 